\title{
CORPUS Corpus
}

Archivos virtuales de la alteridad americana

Vol 2, No 2 | 2012

Julio / Diciembre 2012

\section{Atrocidades civilizadas en la guerra contra los bárbaros. Principios del siglo XIX}

Civilized atrocities in the war against the barbarians. Early 19th century

Juan Francisco Jiménez, Daniel Villar and Sebastián Leandro Alioto

\section{OpenEdition}

Journals

Electronic version

URL: http://journals.openedition.org/corpusarchivos/842

DOI: 10.4000/corpusarchivos.842

ISSN: 1853-8037

Publisher

Diego Escolar

Electronic reference

Juan Francisco Jiménez, Daniel Villar y Sebastián Leandro Alioto, « Atrocidades civilizadas en la guerra contra los bárbaros. Principios del siglo XIX », Corpus [En línea], Vol 2, No 2 | 2012, Publicado el 30 diciembre 2012, consultado el 02 mayo 2019. URL : http://journals.openedition.org/ corpusarchivos/842 ; DOI : 10.4000/corpusarchivos.842

This text was automatically generated on 2 May 2019. 


\section{Atrocidades civilizadas en la guerra contra los bárbaros. Principios del siglo XIX}

Civilized atrocities in the war against the barbarians. Early 19th century

Juan Francisco Jiménez, Daniel Villar and Sebastián Leandro Alioto

\section{EDITOR'S NOTE}

Fecha de recepción del original: 22-08-2012. Fecha de aceptación para publicación: $22 / 10 / 2012$.

\section{Cuando hablan las armas, callan las leyes ${ }^{1}$ Cicerón,} Pro Milone, IV, 11.

\section{Introducción}

1 Los códigos comunes que permiten la comunicación entre quienes comparten un mismo oficio o actividad siempre incluyen sobreentendidos que, salvo situaciones excepcionales, nadie considera necesario explicitar. No sólo porque como es obvio la inmediata comprensión de las personas que están en antecedentes tornaría superflua cualquier explicación, sino porque además un silencio bien administrado tiene su indudable valor (Trouillot, 1995).

2 Así suele ocurrir con la escritura generada en el seno de la tradición burocrática estatal y particularmente con textos militares. Emisores y destinatarios los redactaban sabiendo que una mínima alusión bastaría para que su contraparte comprendiese determinadas cuestiones puestas a su consideración. 
3 Sin embargo, la propia eficacia inmediata de ese tácito y habitual entendimiento crea las condiciones propicias para una eventual ininteligibilidad futura, problema con el que a menudo se enfrentan los historiadores. No obstante, en algunas ocasiones afortunadas para ese lector venidero, un outsider contemporáneo de los hechos develaba con su intervención los contenidos silenciados, al aportar una perspectiva diferente sobre prácticas naturalizadas por los militares y pasadas casi sin palabras en los documentos oficiales.

4 Las prácticas a que aludimos han sido definidas por distintos especialistas como atrocidades, en términos coincidentes: son actos extremos cometidos contra el cuerpo de la víctima -viva o muerta-, con el propósito adicional de amedrentar a otras víctimas potenciales y a quienes presencien la escena. En este orden de ideas, tortura, violación y laceración (o amputación) de partes del cuerpo se consideran comportamientos atroces típicos (Humphrey, 2002; Dwyer, 2009, p. 384, nota 13; Dwyer \& Ryan, 2012, p. XVIII). Michael Humphrey, en el trabajo citado, enfatiza además el carácter transgresivo de la atrocidad: su perpetración excede con creces las expectativas y la comprensión de la víctima o de los testigos, es tan extremadamente horrorosa que aterroriza a quienes la sufren y la presencian y provoca una incredulidad vacilante en aquellos que escuchan su relato (Humphrey 2002, p. VIII). Nadie escapa a los efectos de su tenebrosa pedagogía.

5 Todo ello ocurrió en la oportunidad a la que aquí ha-remos referencia. Los testimonios se eslabonaron de tal forma que permiten reconstruir hoy un conjunto de conductas desarrolladas contra los indios del sur chileno, a partir de acontecimientos que tuvieron lugar durante la Guerra a Muerte, en los campos de Valdivia, a principios del siglo XIX. Hubo frecuentes actos inhumanos; ejecutores y responsables que no aceptaban serlo; un testigo, atónito por las crueldades presenciadas y dispuesto a difundirlas por escrito; y un lejano lector que las puso en duda. El extenso repertorio de perpetraciones consumadas incluyó ausencia de respeto por la vida, honra y afectos de los no beligerantes ${ }^{2}$, apropiación y distribución de sus personas entre los captores ${ }^{3}$, aplicación de tormentos (físicos y psicológicos) para obtener información de los prisioneros -fueran éstos combatientes o no lo fueran $-{ }^{4}$, "remate" en frío de heridos indefensos ${ }^{5}$, ejecuciones sumarias $^{6}$, incautación y reparto de los bienes del enemigo ${ }^{7}$, destrucción total de sus viviendas y plantaciones ${ }^{8}$ y profanación de sepulturas para adueñarse del ajuar funerario.

6 Además de dar cuenta del caso mencionado, en base a los relatos de cuatro protagonistas y a las justificaciones y comentarios que dos de ellos se vieron obligados a esbozar a partir de la intervención crítica del tercero-un outsider-, ensayaremos una respuesta a la pregunta de si las atrocidades militares constituyeron un subproducto de un tipo especial de conflicto -el que tiene lugar cuando sociedades "tribales" se enfrentan con fuerzas de nivel estatal (Ferguson \& Whitehead, 1992; Keeley, 1996)—; si se trataba de "desbordes" circunstanciales condenados y penados por la superioridad o si, por el contrario, conformaban un modo de actuar sistemático; y por último, si las pautas que regían el enfrentamiento de potencias europeas con enemigos coloniales en el mundo periférico eran o no diferentes de las vigentes cuando luchaban contra otros estados occidentales (Howard, 1994).

7 Para examinar las cuestiones propuestas - dejando de lado los partes militares y otras comunicaciones oficiales-, contamos entonces con el testimonio de quienes, en un caso por ser un testigo presencial reactivo, o por su participación en las acciones violentas en 
los restantes, se refirieron - de uno u otro modo- a su perpetración, resignando los últimos a la reserva que, en otro contexto, hubiera dificultado o impedido conocerlas.

\section{La Guerra a Muerte (1818-1824) y la campaña a Pitrufquén de 1822}

8 2.1. Cuando el ejército de San Martín alcanzó en Chile el triunfo decisivo de Maipú (abril 1818), las tropas realistas en fuga buscaron refugio en las zonas meridionales, dirigiéndose a las fronteras y a los territorios mapuche. Entre estos -y en general entre los pobladores de los ámbitos fronterizos- encontraron numerosos aliados que, alarmados por la posibilidad de que el quiebre del estado colonial produjese el de sus propios negocios e intereses, no dudaron en tomar las armas y auxiliarlos con pertrechos, bastimentos e información estratégica, de manera que la resistencia pudiese continuar y prosperar. Simultáneamente, otros vieron en la desgracia de los anteriores la oportunidad de beneficiarse con el nuevo estado de cosas y optaron por sumarse a las filas de los patriotas, determinados a sofocarla. De este modo, se desencadenó la Guerra a Muerte, nombre con el que Benjamín Vicuña Mackenna -su primer historiador (1868) - bautizó a una contienda regional alimenta-da sustancialmente por aquella dinámica puja -según hoy sabemos (Pinto Rodríguez, 1996, p. 35) - y caracterizada por los cruentos enfrentamientos entre cuerpos armados - las montoneras - compuestos por soldados y oficiales de ambas partes en pugna y -sobre todo del lado imperial- por indígenas, pequeños propietarios rurales, comerciantes y campesinos. Durante el extendido desarrollo de las acciones, varios líderes realistas las encabezaron simultánea o sucesivamente; por ejemplo, Palacios en el área valdiviana, quien logró la adhesión de distintos grupos nativos del lugar. El propósito de neutralizar ese foco motivó la organización de un cuerpo expedicionario que partió de Valdivia hacia a fines de 1822.

9 2.2. La columna patriota era comandada por el coronel Jorge Beauchef Isnel e integrada por el capitán William De Vic Tupper Brock, el teniente José Verdugo y el cirujano militar doctor Thomas Leighton, a quienes presentaremos brevemente.

10 Beauchef Isnel (1787-1840) había nacido en la región del Loira Superior. Ingresó tempranamente a la carrera militar, hizo las guerras napoleónicas y fue aprisionado en España en 1808. Huyó más tarde a Estados Unidos de Norteamérica y desde allí pasó a Chile, incorporándose al ejército libertador. Luchó en Cancha Rayada y Maipú y participó en la toma de Valdivia y en las campañas de la frontera sur, oportunidad en la que asumió el comando de la expedición a Pitrufquén de 1822. Una vez retirado, redactó sus memorias, que no fueron publicadas durante su vida sino bien entrado el siglo XX (Feliú Cruz, 1964), aunque sí consultadas en la versión manuscrita por el historiador Diego Barros Arana $(1897,1902)$.

11 Tupper Brock (1800-1830) pertenecía a la gentry de la Isla de Guernsey, en el Canal de la Mancha; estudió desde muy joven en Francia y luego de un intento infructuoso de ingresar al ejército británico, se estableció en Cataluña - donde tenía familiares y se dedicó al comercio. Hacia 1821, tras haberse batido a duelo con resultado fatal para su contrincante, debió exiliarse en Río de Janeiro y desde allí viajó a Buenos Aires y más tarde a Chile, con la intención de iniciar una carrera militar. En Santiago conoció a Beauchef Isnel y este logró que Bernardo o’Higgins lo nombrase capitán de milicias, incorporándolo a la expedición que tomó Valdivia y más tarde a la de Pitrufquén. 
Participó en la guerra del Perú y en ambas campañas de recuperación de la Isla de Chiloé. Llegó al final de su vida en la batalla de Lircay, sumado a las filas constitucionales (Figueroa, 1900, pp. 230-33). Sus memorias y otros documentos fueron publicados en Guernsey como parte de un libro familiar (Family Records) cinco años después de morir Tupper Brock, y sucesivamente reeditados en Londres (1841), Santiago de Chile (1926), Río de Janeiro (1957) y finalmente en Buenos Aires (Tupper, 1972).

Es muy poco lo que sabemos del teniente Verdugo y del doctor Leighton. Del primero, sólo una mención al pasar de Vicuña Mackenna:

Memorias del capitan don José Verdugo, soldado que tomó parte en muchos encuentros de aquella guerra [la Guerra a Muerte], i cuyo trabajo, hecho en Lima en 1852, época en que falleció su autor, conservamos inédito en nuestro poder. Por su naturaleza, i la época tardía en que se escribió (únicamente por reminiscencias), este documento es solo de algun valor en cuanto se refiere a lances personales, i solo en tales casos lo citamos (Vicuña Mackenna, 1868, p. IX).

De acuerdo con esta noticia, unos treinta años después de haber luchado como teniente en la campaña de Pitrufquén, Verdugo falleció en Perú, retirado con el grado de capitán, situación que sugiere una carrera militar modesta y posiblemente breve.

Del cirujano, sabemos menos todavía. El propio Beauchef Isnel -como veremos más adelante- comenta que, luego de aquella traumatizante incursión de 1822, Leighton permaneció radicado en Chile, donde formó familia y continuó el ejercicio de su profesión, adquiriendo la experiencia que a los ojos del coronel le faltaba cuando hizo una "cándida" denuncia de las atrocidades que vio perpetrar en Pitrufquén. Así habrá sido, en efecto: en su historia de la práctica médica chilena, Ricardo Cruz-Coke Madrid, refiriéndose al aporte de extranjeros en el surgimiento de la medicina nacional a principios del siglo XIX, reseña la composición del cuerpo de facultativos en Valparaíso hacia 1827, entre cuyos miembros figura Thomas Leighton (Cruz-Coke Madrid, 1995, p. 287).

\section{Testimonios y argumentaciones acerca de los sucesos de la campaña de 1822}

La incursión de las fuerzas patriotas de Valdivia contra los rebeldes y sus aliados indios duró unos quince días, desde el 19 diciembre de 1822 al 4 enero de 1823. En términos militares, no representó ninguna novedad respecto de otras anteriores: un contingente compuesto por infantería, caballería - criolla y nativa- y artillería penetró en territorio enemigo, con el objetivo de aplastar definitivamente la resistencia realista en la zona de Pitrufquén.

16 Su interés radica, en cambio y según anticipáramos, en la cantidad de testimonios que dejaron los expedicionarios: cuatro protagonistas tomaron la pluma a su turno para redactar un diario (el doctor Leighton), una extensa carta familiar y una narración escueta de los hechos (el capitán Tupper Brock) y memorias (el coronel Beauchef y el teniente Verdugo). Este elaboró el breve texto cedido a Vicuña Mackenna, que es el único hasta hoy inédito: se conserva en el fondo documental que lleva el nombre del historiador, depositado en el Archivo Nacional de Santiago. Esos escritos acompañan este artículo $^{10}$. 
17 Esta excepcional abundancia parcialmente se debió - antes que nada- a que uno de los miembros de la expedición -el cirujano- decidió publicar sus impresiones sobre la misma, en particular las situaciones que lo escandalizaron, volviendo visibles prácticas que de otra forma hubieran quedado en sombras.

18 Leighton, en su doble condición de civil y de extranjero, quedó sorprendido por los eventos presenciados ${ }^{11}$. Su relato, a diferencia de las narraciones militares que tendían a naturalizar conductas agresivas (principalmente con respecto a la población mapuche), reviste el interés de describir la brutalidad de las tácticas de tierra arrasada. El cirujano se vio especialmente conturbado por el tratamiento que recibían los prisioneros, muchos inmolados sin piedad, no sólo por los guerreros bárbaros - de quienes podía esperarse que no la tuvieran debido a su condición de tales-, sino también y sorprendentemente por las propias tropas civilizadas. Enseguida comprendió que su insistencia en presentar quejas ante los mismos militares sería inútil. En un primer momento y a medida que los acontecimientos ocurrían, escribió sobre estos un "curioso diario" - dice Vicuña Mackenna, seguramente sorprendido por el inhabitual tono y contenido de la crítica (1868, p. X) - y más tarde se decidió a difundir los hechos en Europa, enviando el texto a un compatriota y amigo, el ingeniero en minas John Miers.

Leighton conocía las intenciones de Miers de publicar en Londres un libro sobre sus viajes por Argentina y Chile, narraciones que en esa época se habían convertido en un género literario floreciente. En el centro mismo del mundo de entonces, un público numeroso leía con avidez cada nueva obra acerca de las antiguas colonias españolas (Jones, 1986; Pratt, 1998, pp. 254-271) y ese interés amplificó las denuncias del cirujano, asegurándole una audiencia a la que de otro modo no hubiera tenido oportunidad de acceder desde el lejano arrabal americano donde se encontraba.

20 Si los oficiales al mando de la columna hubiesen sido todos criollos resultaría sencillo atribuir su crueldad a la prolongada influencia negativa y concurrente del catolicismo romano y de la educación española, suscribiendo la idea de una suerte de continuidad de la leyenda negra. Sin embargo, el principal responsable -Beauchef Isnel-y Tupper Brock precisamente no lo eran, de manera que cuando la denuncia tomó estado público, ambos se sintieron obligados a pronunciarse.

21 El libro de Miers se editó en 1826 y entre sus lectores estuvo el hermano mayor del capitán Tupper Brock, a quien le escribió sorprendido pidiéndole explicaciones sobre su conducta. En la respuesta - destinada a darlas privadamente- el interpelado no dudó en subrayar la legitimidad de su proceder presentando un sempiterno argumento de largo linaje y frágil consistencia: el trato que recibían los prisioneros indios era la exacta contrapartida del que ellos daban a los soldados que caían en sus manos, descripto este último con un detalle que viniera a compensar de algún modo las crudas referencias que el destinatario de la carta había leído previamente en el diario de Leighton.

Todo esto - dice a su hermano- te parecerá monstruosa-mente cruel, pero debes recordar que las guerras con los in-dios se reducen siempre a exterminaciones; los indios nunca dan cuartel, $y$, en consecuencia, es muy raro que dejen con vida a un hombre blanco que haya caído en su poder. Su modo de ejecutar es este: sostienen al prisionero rígido, completamente desnudo, y lo ubican en un círculo formado por indios a caballo. El jefe entonces galopa y lo coge con la punta de la lanza, arrastrándolo por algunos segundos, teniendo cuidado de no herirlo en alguna parte vital. Esta operación es repetida por todos los caballeros presentes ${ }^{12}$ hasta que su víctima es atravesada en un lugar importante. Tal es el trato que esperamos recibir de los indios. Pensarás, sin embargo, que si el hombre blanco diera un 
ejemplo de moderación estos salvajes lo comprenderían. Siempre se ha tratado de hacer eso y nunca con resultados positivos. No es posible concebir lo brutos y traidores que son y cómo están horriblemente desposeídos de todo sentimiento de humanidad. En verdad, la conducta de los hombres blancos hacia ellos es, por lo general, muy cuidadosa y acompañada de mucha moderación (Tupper, 1972, p. 40, nota al $\left.\mathrm{pie}^{13}\right)$.

Años después, Beauchef Isnel haría un comentario equivalente en sus memorias:

El cirujano inglés Tomas Leighton que acompaño mi división en esta corta campaña, escribió detalladamente un largo diario, relación que hizo imprimir. No recuerdo el título de la obra en que la he leído. Me contentaré con decir que el cirujano Leighton, cuando escribió su carta, no tenía la menor experiencia acerca de estas guerras. Pudo en aquel entonces, haber sido lastimada su filantropía; pero hoy día, que como profesional se ha establecido en el país y que ha adquirido la experiencia necesaria para emitir un juicio madurado largos años, seguramente no escribiría de la misma manera en que lo hizo porque ha tenido ocasión de ver que la filantropía con estos salvajes es una candidez, por no decir una necedad (Beauchef en Feliú Cruz, 1964: 218-219).

23 Con propósitos y en contextos diferentes, ambos oficia-les apelaron, sin embargo, a una misma justificación, a saber: que la conducta seguida en la lucha contra los bárbaros era una adaptación a un tipo especial de conflicto que no admitía la aplicación de las reglas de la guerra "civilizada", porque a la barbarie sólo se la derrota sin dar cuartel.

Al respecto y en un trabajo dedicado al análisis de la conducta de los soldados británicos durante las guerras coloniales del siglo XIX, Simon Harrison explica que, por un lado, la cultura militar diferenciaba claramente la guerra con naciones "civilizadas" de la guerra con naciones "salvajes". Entre las primeras, existían reglas que debían respetarse, mientras que con relación a las segundas sólo era posible combatir con éxito desplegando una brutalidad extrema. Pero por otro lado, los civiles -el hermano de Tupper Brock lo era- asumían que los soldados civilizados debían comportarse civilizadamente siempre (Harrison, 2008, pp. 291-292).

Conscientes de esa expectativa pública, Beauchef Isnel y Tupper Brock discurrieron entonces por la única vía que tenían disponible. Desde su perspectiva, coincidieron en argumentar que las palabras de Leighton superaban la intención "filantrópica" de denunciar atroces perpetraciones cometidas con el consentimiento explícito de quienes por desempeñar el comando- eran tan responsables como sus ejecutores materiales o quizás más que ellos. En realidad, bien leídas y más allá del “cándido" propósito humanitario del "inexperto" redactor, su eficacia consistía precisamente en exhibir al desnudo - aunque fuera de manera no deliberada- los crudos pero inevitables efectos originados en la suspensión de una norma que no se aplicaba a la guerra con los “salvajes". Tal interpretación - mutatis mutandi-, venía en último término a colocar en cabeza de estos la verdadera responsabilidad de desencadenar las prácticas afligentes: eran ellos con su previo y simétrico furor los que sólo dejaban margen para que se los combatiera de esa forma. Lo contrario, esto es, guerrear en su contra respetando de las normas de la guerra "civilizada", hubiera sido una decisión suicida destinada al fracaso ${ }^{14}$. 


\section{Las leyes de la guerra en las fronteras de la periferia imperial}

bárbaros no representaron un quebrantamiento de las leyes de la guerra, sino lo contrario. Emer de Vattel, teórico prominente del ius gentium iluminista, defendía en su obra el uso de la violencia con fines pedagógicos para con cierta clase de enemigos:

Cuando se está en guerra con una nación feroz, que no observa reglas ningunas ni sabe dar cuartel, se la puede castigar en la persona de los prisioneros que se hacen (pues son del numero de los culpables), y tratar por este rigor de reducirla á las leyes de la humanidad; pero siempre que la severidad no es absolutamente necesaria, se debe usar de la clemencia (Vattel 1834, p. 114, el resaltado nos pertenece).

Su disquisición es consistente con una tradición occidental muy antigua. Históricamente, las reglas habían experimentado variantes según quiénes fueran los que se enfrentaban, de manera que las normas de buen trato a no combatientes y prisioneros sólo se aplicaban si los contendientes se consideraban pares. Los guerreros de las distintas poleis griegas del período arcaico, aunque respetaban las regulaciones que se aceptaban vigentes entre ellas, no trepidaron en descartarlas en las contiendas con los persas (Ober 1994). La impiedad de los romanos reforzó su fama bélica: de hecho, aún en la Edad Media, el enfrentamiento sin cuartel continuaba denominándose bellum Romanum (Stacey, 1994). En esa misma época, ciertas normas eran respetadas en las guerras entre reyes cristianos, pero devenían inaplicables cuando se luchaba contra infieles (por caso, musulmanes). No obstante que en la Europa moderna fueran delineándose políticas de atenuación de las consecuencias de la beligerancia (Parker, 1994), algunos grupos de personas permanecieron excluidos de cualquier forma de la conmiseración: los considerados rebeldes, los paganos y los bárbaros (Howard, 1994, p. 5). Los indios, capaces a los ojos occidentales de reunir en sí hasta las tres condiciones juntas y a quienes se acusaba de no respetar ninguna ley, únicamente merecían que se les pagara con más barbarie.

Sin embargo, aunque muy instalada, la idea de que el uso intensivo de la violencia irrestricta constituía un vestigio de incivilidad o salvajismo resiste mal el análisis histórico de los procedimientos puestos en ejecución por los propios estados civilizados. En buen número de casos, sus mismos ejércitos la aplicaron sin pausa desde que se elaboró aquella noción en tiempos arcaicos hasta la actualidad (Levene, 1999, pp. 9-11). Que el uso del rigor ilimitado constituya una lógica adaptación al combate con bárbaros -como aducían los militares- es un argumento que encuentra único apoyo en el hecho indiscutible de que los civilizados no reconocían como pares a sus contendientes y, por lo tanto, no los consideraban merecedores de piedad. Sobre todo en las oportunidades en que tenían una superioridad bélica circunstancial, actuaban sin atenerse a ninguna restricción.

La violencia que no respeta límites sólo excepcionalmente es casual o constituye un desborde irracional imposible de frenar a tiempo. De ordinario, su uso estratégico está previsto y se la aplica para sembrar el miedo y obligar a los enemigos a desistir, o a disuadir a quienes pudieran apoyarlos (Parker, 1994; Goldhagen, 2010) ${ }^{15}$. Por eso mismo, la rebeldía es fuertemente sancionada. Los españoles primero y luego sus descendientes criollos utilizaron la ficción de considerar rebeldes a quienes en realidad nunca se les habían subordinado ${ }^{16}$; esa supuesta rebeldía los haría acreedores del más severo de los 
castigos, dado que los perpetradores reputaban firmemente aceptada la prescripción de que la infidelidad y la traición no pueden tener perdón.

Las conductas atroces no constituían excesos de soldados perturbados cometidos al amparo de la ignorancia o por negligencia disciplinadora de los mandos, sino un modo de actuar planeado y autorizado por los oficiales y en general convalidado por los superiores y autoridades jerárquicas. Pero el hecho de que todos compartieran un código de tratamiento bélico de los bárbaros que incluía la necesaria ejecución de atrocidades aleccionadoras, con frecuencia hace que ellas no se mencionen, dándolas por sobreentendidas en tanto se trataba del procedimiento normal que todos conocían y aprobaban.

La revolución de independencia produjo un cambio importante en este aspecto, que contribuye a explicar una conducta como la de Thomas Leighton en el caso aludido aquí. La apertura comercial y política impulsó a muchos extranjeros no hispanos a conocer Sudamérica, a recorrer sus territorios e interiorizarse de sus realidades y potencialidades. Muchos empezaron a escribir al respecto en Europa, donde la modernidad dio paulatinamente lugar a una mayor conciencia de lo que ocurría en el resto del mundo. Esa opinión pública -civil y laica- a menudo rechazó la brutalidad de la guerra periférica. Entonces, aquello que militares, misioneros y burócratas habían creído legítimo, ahora no sólo podría salir a la luz, sino que - una vez conocido- demandaba una justificación que en otros contextos se hubiera considerado fútil. Esta justificación se apoyó entonces en la supuesta inevitabilidad de ese comportamiento feroz cuando se enfrenta a enemigos que no dan cuartel: para sobrevivir es imprescindible responder del mismo modo. El argumento tuvo larga vida (aún hoy perdura, como es tristemente notorio). Pero limitándonos al siglo XIX y a las contiendas con los nativos, diremos que se utilizó hasta la derrota militar y subsiguiente pérdida de autonomía y subalternización de los grupos regionales.

Las pruebas de su falsedad son abundantes e incluyen las referidas al tratamiento que los estados civilizados dieron a los considerados rebeldes dentro de la misma Europa y de sus fronteras, sin participación alguna de bárbaros. Las guerras de religión del siglo XVI, la represión española en Flandes, o los hechos de la Segunda Guerra Mundial son unos pocos ejemplos tomados al azar, que podrían multiplicarse casi indefinidamente. 


\section{Anexos}

\section{1) LEIGHTON, Thomas. 1826. Journal of a Military} Expedition into the Indian Territory in Travels in Chile and La Plata including accounts respecting Geography, Geology, Statistics, Government, Finances, Agriculture, Manners and Customs and the Mining Operations in Chile. Collected during a residence of several years in these countries. By John MIERS. Illustrated with original maps, views, \&c. In Two Volumes. London: Printed for Baldwin, Cradock, and Joy. 1826, volume 2, 472-503.

Traducción del inglés: Juan Francisco JIMÉNEZ ${ }^{17}$

/472/ "El relato que le envío", dice el Dr. Leighton, “es un extracto de mi diario, que llevé bastante regular-mente desde mi llegada; Usted percibirá que está escrito apresuradamente y sin cuidado. En la situación en que con frecuencia me encontré no podía ser de otra manera; sin embargo, como siempre anoté las circunstancias tan pronto como era posible después de que ocurrieron, confío en su corrección y es probable que, si ahora intentase reducirlo o ampliarlo en detalle, perdiera parte de su interés.

"Valdivia, Diciembre 16, 1822. Trescientos infantes fueron embarcados en canoas, y avanzaron río arriba (el Tres Cruces) hacia el lugar de reunión designado en la frontera India; un único traje de lona, una piel de oveja sobre la que yacer, un poncho para vestir en tiempo lluvioso y para servir como cobertura durante la noche, un mosquete y bayoneta, con sesenta rondas de munición, completaban el equipo de cada soldado; ni bagajes ni tiendas se consideraron necesarias, $y$, en lo tocante a las provisiones, se confiaba en la ayuda de los Indios amigos, o en lo que pudiera tomarse del enemigo.

"Diciembre 17.- A las once a. m., embarqué con el Coronel Beauchef, y luego de cuatro horas de duro remar, arribé a Tres Cruces: este es un pequeño fuerte, dignificado en los mapas Españoles con el nombre de castillo: /473/ está distante unas nueve leguas de Valdivia, y se sitúa en la ribera norte del río que pasa a través de esta ciudad: el fuerte es simplemente un espacio cuadrangular en la cima de un montículo de tierra, delimitado por unas burdas empalizadas, y rodeado por un foso seco; dentro del mismo hay montada una pequeña pieza de campaña en cada ángulo, y se erigieron cabañas o barracas para el acomodo de unos cincuenta hombres: fue construido por los Españoles como una defensa contra los Indios; frecuentemente ha demostrado no ser adecuado para este propósito; incluso el año pasado los Indios lo tomaron al asalto, masacraron la guarnición, y quemaron la aldea vecina. Después de descansar aquí una hora, proseguimos nuestra ruta a caballo, atravesando un espeso bosque, y al caer el sol llegamos a San José, distante cinco leguas de Tres Cruces: este era el lugar del encuentro; el Mayor Rodríguez, con la infantería, el capitán L'Abbè con su compañía de caballería, y unos sesenta Indios de las vecindades, habían acampado unas horas antes de nuestra llegada: la apariencia de estos indios, de ninguna manera confirmó la idea que me había formado previamente de ellos; 
parecen sumamente afeminados y sumisos; están por debajo de la estatura común, de tez oscura, rostro redondo y lleno, ojos negros pequeños y penetrantes, muy poca frente, la cabeza cubierta de abundante cabello, en muchos casos casi alcanzando las cejas, narices planas con aberturas amplias, bocas grandes, dientes blancos y regulares, con la excepción de los dentes canini superiores, que son en general muy grandes y largos; no tienen barbas, sus cuerpos muy musculosos, sus piernas desproporcionadamente cortas y generalmente arqueadas.

cacique usaba un sombrero y plumas; los demás /474/ en general iban descubiertos; algunos tenían su largo cabello negro flotando libremente sobre sus hombros, mientras que otros lo ataban en un nudo sobre la coronilla, pero todos tenían la cabeza rodeada por un pedazo de listón o cinta, generalmente roja, que añadía mucho al afeminamiento de sus semblantes. Sus vestimentas son muy simples; el vestido inferior consiste en un pedazo de paño de lana que rodea la cintura y alcanza aproximadamente los tobillos; el superior, o poncho, es asimismo un paño de lana, de dos yardas de largo y una yarda y media de ancho, con un tajo en el medio, suficiente para dejar pasar la cabeza.

Varios estaban vestidos con viejos uniformes españoles, algunos llevaban calzas despojadas del pie, pero ninguno usaba zapatos, ni sustitutos para ellos, algunos tenían espuelas de cobre, cuyas rodajas medían una pulgada y media de diámetro; pero, en su mayoría, sus talones estaban equipados con espuelas de madera aguzadas. Cada indio llevaba su lanza, un arma sumamente engorrosa; la punta es generalmente la hoja de un cuchillo, una bayoneta rota, o un pedazo de duela afilado y enderezado, atado al extremo de una caña de entre ocho y doce yardas de largo. Observé que algunas de las lanzas habían sido forjadas y templadas por la mano del herrero, y comprendí que les habían sido provistas por los patriotas el año pasado. La lanza se usa a caballo, o a pie cuando el campo de acción es montañoso o boscoso: nunca se arroja, sino que, al iniciar una carga, el asta es fuertemente apretada entre el codo y el costado derecho, tanto en riestre como apoyada: siempre se enfila con la mano derecha y es dirigida por ella. Cuando un Indio es perseguido, nunca abandona su lanza, sino que la arrastra tras de sí. /475/ Los caciques portan espadas, y todos los Indios tienen machetes, cuchillos largos y pesados de hoja ancha, que sirven para cortar y hender; y sin estos no podrían abrirse camino a través de los matorrales de arbustos rastreros que cubren el país. Aunque son muy diestros en el arte de lanzar el lazo, no parecen usarlo como arma ofensiva, ni vi ninguna de las bolas o armas arrojadizas que vuelven tan formidables a los Indios pampas. Los caballos que he visto hasta ahora son criaturas diminutas y poco fogosas. Unas pocas pieles de ovejas y una silla de madera excavada del tronco sólido de un árbol, a la que se añaden dos pequeños estribos de madera, tan pequeños que sólo se puede meter en ellos el dedo gordo del pie, componen los arreos de montar, de tal manera que las espaldas de los pobres animales siempre están desolladas. El cacique tenía una vieja silla y bridas españolas, chapeadas en plata, y estribos de plata que pesaban al menos diez libras cada uno.

39 "Diciembre 18.- Retomamos nuestra marcha al alba. Veinte Indios la encabezan a unas 100 yardas adelante del resto; les sigue la caballería, y luego la infantería; una pequeña guardia va en la retaguardia con el reducido bagaje que llevamos. Con nosotros marcha todo el cuerpo de Indios en un estado de confusión muy clamoroso, que se mantuvo todo el día alimentado por la continua incorporación de pequeñas partidas; marchamos unas siete leguas a través de un país bien arbolado y con agua. A las cuatro p. m. nos detuvimos en una pequeña aldea llamada Cheskè; fue incendiada el año pasado por el Mayor 
Rodríguez; muchas plantas y cardos crecían en las callejuelas, y las cercas estropeadas y los huertos de manzanos señalaban /476/ los sitios de residencia de una población que debió ser medianamente numerosa. Unos pocos postes carbonizados de las viviendas testimoniaban que la mano de los destructores había pasado por allí. En nuestra marcha hacia esta aldea en ruinas, llamó de repente mi atención que los Indios lanzaran un grito horrendo y se dispersaran inmediatamente.

"Parece que en la marcha de avance se había visto a un Indio solitario, que de inmediato abandonó su caballo y se zambulló en la espesura; se sospechaba que era un espía (un bicho $\left.{ }^{18}\right)$, y los Indios, que no se manifestaban urgidos por buscarlo, fueron animados a hacerlo. Nada puedo encontrar comparable con esta escena, a excepción de una partida de podencos liberados de su correa: algunos salieron al galope para bloquear los pasos, otros desmontaron y golpeaban las matas con sus lanzas, reptando a ratos sobre manos y rodillas, poniendo sus orejas sobre el terreno, e incluso olfateando, como si pudieran descubrir el rastro de su enemigo por el aroma. Me apiadé del pobre hombre, porque su escape me pareció imposible. Tan pronto como se ubicaron los centinelas y se despejó el terreno para el campamento, fueron sacrificados varios novillos y en un momento se hicieron visibles cientos de fuegos.

Incomodado por el calor y el vívido resplandor que se dispersaba en todas las direcciones, me retiré de la bulliciosa escena y me senté debajo de un manzano, al tiempo que la novedad de mi situación, el fulgor de los fuegos reflejándose en los morenos semblantes de los soldados atareados en asar la carne todavía palpitante de los animales y los gritos incesantes de los indios ofrecían abundante material para el ejercicio de la imaginación.

"Diciembre 19.- El indio visto la última noche fue traído mientras nos preparábamos para la marcha; /477/ el pobre diablo estaba desnudo hasta la cintura, sus manos atadas a la espalda y un gran terror reflejado fuertemente en su semblante. Tan pronto como este desgraciado pudo recuperarse de su extrema agitación, declaró que había dejado a su amo, Pedro Xaramillo, con el propósito de reconocer la ruta; que su amo estaba viajando hacia Valdivia con la intención de rendirse; y que, al ver sólo Indios armados, había pensado que se trataba de un cuerpo enemigo que marchaba sobre su tribu; y consciente de que podían matarlo en el terreno sin escucharlo o dar crédito a cualquier cosa que les contara, había intentado escapar. Me enteré que este Pedro Xaramillo era el segundo hijo de un viejo Español que huyó a los Indios, cuando las fuerzas patriotas tomaron posesión por primera vez de Valdivia: el anciano, conocido entre los Indios por el nombre de Calcaref, poseía una gran influencia en todas las tribus, había demostrado mucha hostilidad contra los patriotas y acompañaba a la partida que sorprendió Tres Cruces el año pasado; en esta ocasión mostró tanta determinación en vengarse que mató con su propia mano a uno de sus parientes que comandaba el fuerte: en realidad, había sido el autor y líder de cada ataque hostil contra los patriotas de Valdivia: tiene tres hijos, el mayor de los cuales fue tomado prisionero dos días antes del comienzo de la campaña, cuando intentaba pasar hacia Chiloé con cartas de su padre: el segundo, Pedro, es perseguido por su propio padre por haber manifestado adhesión a la causa patriota; el menor comanda un cuerpo de Indios bajo la dirección de su padre. Luego de que el atemorizado /478/ Indio relató su historia, se le devolvieron sus ropas y fue enviado de regreso con su amo, Pedro Xaramillo, para garantizarle la protección del coronel y al mismo tiempo se le envió un mensaje, informándole que su hijo mayor todavía permanecía prisionero y que sólo se preservaría su vida bajo la condición de que Palacios (otro temerario refugiado) y sus seguidores fueran entregados, algo que el anciano, dada 
su influencia entre los Indios, podía lograr con facilidad. Durante la marcha de hoy, pasamos varias viviendas Indias, todas eran pequeñas y extremadamente tos-cas en su construcción, formadas solo por ásperos postes clavados uno al lado de otro en el terreno y techadas con paja, una abertura estrecha y baja servía al propósito de una puerta y algunas de ellas presentaban un orificio en el techo para permitir la salida del humo. Unas pocas eran grandes y cuadradas y sus paredes parecían estar hechas de arcilla, pero construidas sin atención a la regularidad o consideración al confort. Sus habitantes las habían abandonado muy recientemente, pues las cenizas de sus hogares todavía estaban calientes. No vi utensilios de ningún tipo, excepto una larga batea al lado de cada choza, excavada en el tronco de un árbol y en la que machacaban las manzanas para hacer chicha. Cada una de estas cabañas tenía en su vecindad un recinto cercado cultivado con gran cuidado: el maíz y las judías blancas grandes parecían ser los principales productos, aunque también vi patatas, guisantes, cebada y trigo cuya apariencia hubiera reportado crédito a un granjero inglés. Sobre el mediodía hicimos alto al lado de un pequeño arroyo. Aquí varios ancianos Indios nos trajeron un líquido lechoso en ollitas /479/ de greda, el que probé, encontrándome con que era una bebida fermentada de un agradable sabor ligeramente ácido: al estar agotado y sediento, tome un gran trago y lo hallé muy refrescante. Invité entonces a mis compañeros a participar de mi deleite, pero rehusaron, riéndose de mí y explicándome lo que había bebido. Se me dijo que el licor era preparado con manzanas muy inmaduras: cuando aún no habían adquirido mucha sacarina, las ancianas las masticaban y escupían el jugo mezclado con saliva en una marmita de greda, donde fermentaba rápidamente y se transformaba en el brebaje que yo había probado. Pronto expulsé todo lo que había tomado, formulando el voto tácito de no beber o comer nunca más cualquier cosa preparada por las manos de un Indio. Tuve la curiosidad de ir a ver la elaboración de esta bebida nauseabunda: cuatro viejas horrendas y un niño estaban sentados en el suelo sobre sus traseros, diligentemente dedicados a masticar manzanas y derramar el jugo en una gran cacerola de arcilla ubicada en el centro; de tanto en tanto, tomaban un poco de agua y el chico removía frecuentemente el líquido con una pequeña rama de canelo.

"En la tarde llegamos a Calfacura, la residencia de un poderoso cacique de ese nombre. Este hombre previamente prestó ayuda a los españoles refugiados, pero el año anterior, severamente castigado por el Mayor Rodríguez, se había convertido en un patriota. Era un viejo muy feo, y tan sumamente corpulento que me asombré de que fuera posible que caminase; hizo un largo discurso en atenuación de su pasada conducta y concluyó haciendo el ofrecimiento propiciatorio de cinco bueyes gordos, lo que en esta ocasión constituía un abastecimiento /480/ muy oportuno. El Mayor Rodríguez me in-dicó el lugar donde el año anterior le disparó a un Indio; su relato me heló la sangre. Parece que al atacar el lugar, sólo pudo sorprender a una mujer, su hijo y su hija: esta última era una niña. La tribu había logrado escapar a sus escondites en los bosques: en vano se amenazó a la mujer y a su hijo con una muerte inmediata si no revelaban estos sitios ocultos, tampoco tuvieron éxito las promesas de recompensa; hasta que, enfurecido por su obcecación, el inhumano mayor obligó al hijo a arrodillarse, postura en la que le disparó un tiro en presencia de la enajenada mujer y aterrorizada niña. Aún así la madre permanecía obstinada y cuando se le hizo arrodillarse y los mosquetes le apuntaron, la niña se precipito hacia los asesinos, rogándoles que perdonaran la vida a su madre y que ella les conduciría al refugio donde se encontraban su padre y sus hermanos; la madre se incorporó enfurecida, abalanzándose sobre su hija a la que intentó estrangular. La niña fue rescatada de sus garras y conducida al lugar donde había señalado el refugio, mientras 
la madre la reconvenía por su degeneración y falta de coraje. Finalmente expiró en agonía al percibir la matanza de toda su familia, maldiciendo con sus últimos alientos a los implacables asesinos!

"Nuestros auxiliares Indios sumaban ahora unos 200 hombres y estaban bajo el mando de un jefe que llevaba el rango de capitán de nuestro ejército y el título de comisario de Indios: oficiaba como su magistrado en tiempo de paz, y como general durante /481/ la guerra. Observé que cada Indio portaba una bolsa fabricada con la piel completa de una cabra, llena con harina ordinaria, pude ver que era harina de cebada; la preparan sus mujeres, que tuestan el grano y lo muelen entre dos piedras. Los Indios están muy apegados a esta comida, que mezclan con agua hasta darle la consistencia de unas gachas gruesas, y le llaman ulpa. Aunque el recuerdo de la chicha todavía estaba fresco en mi memoria, me animé a probar la ulpa, y la encontré tan buena que me determiné a no beber nada más durante la marcha. Esta noche tuvimos una maravillosa vista del volcán de Villa Rica, que se yergue hacia el este a unas veinte leguas de distancia. Un brillo rojizo se observaba a una considerable altura sobre el cráter; no parecía ni un reflejo, ni una nube, sino más bien una cortina de fuego líquido suspendida en el aire que no cambiaba su situación ni su forma. Alrededor de cada cuatro segundos, de la boca del cráter surgía una luz, al principio de un rojo desvaído, se volvía nítida con rapidez y luego moría gradualmente. Cuando la luz del cráter se tornaba más nítida, la expansión roja descripta en primer término no era observable, pero reaparecía gradualmente a medida que aquella luz decrecía.

"Diciembre 20.- Avanzamos unas cinco leguas, el camino atravesaba un bosque denso y era muy malo. A la noche, alcanzamos un claro donde levantamos nuestras tiendas. Estaba muy fatigado con este día de marcha, porque habíamos atravesado un bosque aburrido y deprimente, en el que la espesura no dejaba ver ni un pájaro. La estrechez y precariedad del camino /482/ impedían toda oportunidad para la conversación y dado que se requería toda mi atención para evitar que el caballo tropezara, me vi incluso privado de la meditación.

"Diciembre 21.- Recomenzamos nuestra marcha antes del alba y continuamos con gran perseverancia durante el día para llegar a Pituvquin $^{19}$ antes de que oscureciera; los caminos eran muy malos, y en algunas partes se volvían intransitables por una especie de arbusto rastrero, llamado Quilo $^{20}$ que tiene un crecimiento notablemente rápido $\mathrm{y}$ obstruye las rutas en pocos días. Los estrechos y poco frecuentados caminos a través de estas florestas, se vuelven pronto infranqueables. Esto nos ocasionó muchas molestias; las tropas eran obligadas con frecuencia a detenerse, a estar de pie con el agua hasta sus rodillas, mientras los indios despejaban el camino con sus machetes. Nuestras caras y manos estaban seriamente rasguñadas y rasgadas nuestras ropas. Los que íbamos montados recibimos las molestias más grandes, porque con frecuencia nos enredábamos tanto que nuestros caballos continuaban su marcha debajo de nosotros. Hacia el mediodía, nuestro progreso se vio interrumpido por un río tan profundo que no habría sido transitable si no fuera por un reborde de rocas que lo cruzaba oblicuamente sobre el que la corriente corría con tal velocidad que vadearlo se convertía en un asunto serio. Varios de nuestros hombres resultaron arrastrados y sólo los salvó la diligencia de los Indios, que eran todos diestros nadadores. Poco antes del anochecer salimos del bosque y fuimos recompensados por la vista de un hermoso paisaje, extendido hasta donde llegaba nuestra mirada: estaba cubierto por el verdor más /483/ delicioso y lo atravesaba un ancho río, tan terso y transparente como el cristal, que fluía hacia el mar. Hacia el este, la 
Cordillera semejaba un negro bastión, estupendo e impenetrable, que vedara todo progreso en esa dirección. Estaba presidida por el majestuoso cono cubierto de nieve del volcán de Villarica, al que nos habíamos acercado estrechamente.

En este delicioso valle no se distinguía el menor vestigio de habitación humana. Oscureció antes de que llegásemos a la ribera del río y para nuestra gran desilusión, no encontramos a nadie que nos recibiera, pues esperábamos que se nos reunieran 1000 Indios amigos y así obtener el suministro de provisiones que necesitábamos mucho. La mortificación se marcó en todos los semblantes; oprimidos por la fatiga y el hambre, se aposentaron con la perspectiva de verse obligados al día siguiente a sacrificar sus jamelgos para subsistir. Esa noche intenté observar la apariencia del volcán; pero agotado por la jornada, pronto fui superado por el sueño e insensible-mente extravié en el olvido todo recuerdo del romántico lugar en el que me encontraba.

"Domingo, Diciembre 22.- El sol había alcanzado una altura considerable antes de que yo me liberase de mi inconsciencia; me despertaron todos los poderes de los rayos solares actuando con fuerza sobre mi rostro y encontré a nuestro campamento en movimiento. Unos pocos Indios habían llegado, trayendo consigo cuatro novillos que no se consintió que continuaran vivos por más tiempo; la apatía ocasionada por la fatiga de ayer fue reemplazada por una actividad inusual y el / 484 / apetito más voraz.

En menos de diez minutos, los animales fueron sacrificados, destazados, y cada hombre tuvo su porción ya chisporroteando y asándose sobre el fuego. Como se ordenó que las tropas descansaran aquí este día, fui a reconocer las vecindades y a cada paso observé las cenizas de alguna vivienda India recientemente destruida. Toda la tierra parecía haber sido cultivada hacía poco tiempo; manzanos y perales eran muy abundantes y existían muchos indicios de que una comunidad numerosa había habitado las riberas del río. Varias tribus de los alrededores aliadas entre sí destruyeron esta aldea de Pitovquin, instigadas por los refugiados Españoles, debido a que los Indios de Pitovquin se unieron a la causa patriota. Unos pocos que lograron escapar de la venganza del fuego y la espada todavía eran cazados como bestias en los bosques por sus enemigos. Encontramos abundancia de papas y judías creciendo silvestres y todo el país estaba profusamente cubierto con frutillas salvajes de un sabor muy delicioso. Esta noche registré que la combustión del volcán de Villarica seguía tan activa y tan brillante como en la noche del 19.

"Diciembre 23.- Recibimos reportes de que Palacios estaba a unas pocas leguas de nosotros y que avanzaba hacia nuestro campamento, bajo la sospecha de que aquí sólo los Indios estaban reuniendo sus fuerzas con el propósito de invadir sus posesiones. El Coronel Beauchef determinó sorprenderlo si fuera posible y con esta intención seleccionó 100 hombres de la infantería, /485/ a quienes reunió con 50 jinetes y todos los indios auxiliares bajo el comando del mayor Rodríguez y como era probable que hubiera algo de lucha, se me ordenó que los acompañara. El coronel permanecería a retaguardia con el resto de su fuerza, intentando cruzar el río y avanzar hacia Borroa, donde suponía que se situaban los cuarte-les generales del enemigo. Partimos de conformidad con lo dispuesto y después de marchar durante dos leguas, hicimos un alto para refrescar a nuestros hombres. En este momento, los Indios realizaron un simulacro de lucha, a veces cargando a todo galope, otras desmontando y peleando a pie; produjeron una gran gritería, aunque en sus maniobras, si así pudiera denominárselas, no parecía existir la menor regularidad o disciplina. En algunas de sus cargas, se aproximaron tanto a nosotros que el mayor, sospechando una traición, ordenó a nuestras tropas cargar sus armas y permanecer 
preparados. Aunque no existieran motivos para estas sospechas, posteriormente quedaría demostrado que la precaución fue afortunada. Después de una corta consulta, se determinó enviar a cincuenta de los Indios mejor montados a explorar el camino; así se hizo, la caballería pasó a través de un profundo cenagal y desapareció en el bosque y la infantería, en su intento de seguirla, pronto se hundió en el lodo hasta encima de la cintura: en este momento excitó nuestra atención un ruido confuso y pronto distinguimos la voz del capitán L'Abbè llamando a los Indios para que avanzasen -requerimiento que obedecieron con la mayor presteza.

51 Estuve entre los últimos que pasaron la Barranca y encontré a las tropas en cierto desorden, encerrados en un área pequeña rodeada por profundos acantilados llenos de grandes árboles y arbustos impenetrables que solo tenía /486/ dos salidas; una, el paso por el que habíamos entrado desde la Barranca -la otra, un estrecho paso opuesto a ella que conducía al bosque ubicado más arriba. Los cincuenta Indios enviados en avanzada se habían dado inesperadamente de bruces con el enemigo y fueron instantáneamente derrotados; al retroceder, cayeron sobre nuestra caballería y junto con ella sobre la infantería, quedando todos apiñados en el área pequeña ya descrita. El orden se restableció rápidamente, formando la infantería en línea, la caballería en el flanco derecho y los Indios en el izquierdo. Enseguida percibimos que el enemigo comenzaba a avanzar precipitada-mente hacia nosotros desde arriba; los gritos horribles que llenaban el aire anunciaban que el bosque estaba lleno de ellos. En este momento de temeroso suspenso, se despachó un correo a Pitovquin para informar al coronel de nuestra situación. Sólo teníamos dos alternativas; o nos retirábamos a nuestro cuartel general, o forzábamos el paso controlado por los Indios; fue elegida esta última: un sargento y cinco hombres condujeron el avance, siendo precedida su carga por una andana-da de mosquetes, porque debido a lo cerrado del bosque no podíamos ver más allá de diez yardas delante de nosotros. La infantería avanzó luego en una columna y después de la primera descarga de mosquetes, los gritos de nuestros auxiliares Indios y el resonar de los cascos de los caballos nos anunció que el enemigo había huido. Por mi parte, me apresuraba en la retaguardia, primero pisando lanzas rotas y luego los cuerpos de los Indios muertos y agonizantes que ofrecían la visión mas espantosa que nunca vi: previamente desnudos para el combate y extendidos sobre el terreno, se retorcían en las agonías de la muerte y /487/ mordían el polvo mientras su sangre fluía lentamente de las grandes heridas, excepto cuando era propulsada más profusamente por sus profundos suspiros y lamentaciones. A medida que pasaban a su lado, nuestros soldados remataban a estos pobres miserables, no por algún sentimiento de humanidad, sino por uno de salvaje barbarie. Pronto llegamos a un espacio despejado, desde donde podía verse al enemigo huyendo a la distancia, envuelto en una nube de polvo: tuvieron éxito en lograr su escape; debido a que estaban mucho mejor montados que nuestra caballería, se abandonó la persecución.

Mientras descansábamos sobre nuestras armas, fuimos agradablemente sorprendidos por el regreso del Sr. Arengoen, un caballero sueco que acompañó el avance de la partida de Indios y de quien nos imaginábamos que había sido tomado prisionero. Nos contó que al principio cabalgó osadamente en medio del enemigo, pensando que se trataba de una partida de Indios en camino a reunirse con nosotros, sólo descubrió su error al recibir la embestida de una lanza India, que detuvo disparándole un pistoletazo al agresor; luego clavó espuelas y se internó en la espesura, desde donde escuchó claramente el fuego de los mosquetes que lo condujo hacia nosotros. Poco después trajeron un prisionero, sus 
captores lo habían desnudado totalmente, conduciéndolo montado en una mula a la presencia del mayor. Al principio intentó negar que hubiera tomado las armas en nuestra contra; pero cuando se le presentaron pruebas, no pudo extraérsele una palabra más: fue nuevamente enviado a los Indios, que lo apartaron unos pocos pasos y procedieron a ejecutarlo con frialdad.

Yo no esperaba que semejante barbarie se tolerara /488/ delante de soldados Cristianos y quedé escandalizado al ser testigo de tal inhumanidad. Un cacique le dio el primer golpe sobre la cabeza con un sable, después fue despachado con repetidos lanzazos y estocadas. La víctima demostró ese coraje pasivo que a menudo se encuentra entre los bárbaros: al encontrar vana toda resistencia y todo escape sin esperanza, aunque los primeros golpes no fueron mortales, no grito ni gimió, sino que apretó sus dientes y reprimió su respiración, sufriendo pacientemente todo su dolor hasta que finalmente sus feroces asesinos lo ultimaron. Nuestros oficiales y soldados miraron con la mayor sang froid, más aún, con secreto placer, como si estuvieran acostumbrados a espectáculos similares. Observé que cada indio clavó su lanza en el cuerpo de la víctima y me dijeron que entre ellos se considera deshonroso volver al hogar luego de una expedición bélica sin haber mojado sus lanzas en la sangre del enemigo. Encontré también que era una costumbre invariable entre los Indios matar inmediatamente a sus prisioneros; -siempre se exceptúa a los caciques de esta regla, ellos son rescatados; así, igualmente, los ancianos, por los que, en ocasiones, muestran un gran respeto. Hacia el ocaso acampamos al costado de un pequeño río, a alguna distancia más allá del cual, sobre la ribera opuesta, también descansó el enemigo. Aquí descubrimos a un Indio herido que fue inmediatamente ejecutado. Nuestras pérdidas del día fueron un Indio muerto y un soldado de caballería herido; las del enemigo se estimaron en alrededor de treinta muertos.

Pasamos la noche en continua zozobra, debido a la gran bulla y confusión que provenía del campamento enemigo; /489/ la gritería se oía claramente. Pude dormir poco, porque mi imaginación era presa de las crueles escenas presenciadas durante el día y cientos de veces me condolí de verme asociado con tales monstruos inhumanos.

"Diciembre 24.- Esta mañana, al rayar el alba, fueron conducidos tres prisioneros desnudos, ejecutándolos instantáneamente. Hacia las ocho, a. m., el coronel se unió a nosotros con el resto de la fuerza. Pudo haber llegado anoche, pero ni con promesas ni con amenazas logró persuadir a sus guías Indios de que atravesaran el campo de batalla después del ocaso; en cuanto vieron los cuerpos de los muertos esparcidos sobre el terreno rehusaron continuar. Avanzamos ahora, sin pérdida de tiempo, en persecución del enemigo, pero partieron antes que nosotros y no vemos señal de ellos. Nuestra ruta sigue la margen izquierda del río anteriormente mencionado. El terreno es uniformemente llano y superamos varios campos cercados en donde crecen porotos y guisantes bien cultivados: en uno de ellos sorprendimos a una mujer y un niño, quienes, aterrorizados por las amenazas, nos condujeron hacia la familia: que consistía en un Indio viejo, su hijo, tres mujeres jóvenes y cinco niños, dos de ellos de pecho. Dos de las mujeres jóvenes eran realmente bellas, una en particular que tenía ojos azules y una tez hermosa y sonrosada. Los hombres quedaron a cargo de la guardia; las mujeres y niños fueron tomados por los Indios con una avidez que demostraba lo mucho que valoraban su presa. Las mujeres no parecieron preocuparse mucho por el cambio de amos, sino que montaron detrás de sus nuevos pretendientes con aparente indiferencia /490/ y entraron de inmediato en íntima conversación con ellos. La separación de sus niños no pareció afectarlas mucho más, porque aunque derramaron unas pocas lágrimas, ni los abrazaron 
ni los besaron. Hacia las 5, p. m., acampamos en un gran sembrado de porotos próximos al tiempo de la cosecha, ofreciendo un buen abastecimiento para nuestras tropas. Este terreno se me antojó el más encantador que hubiese visto jamás, con tal combinación de bosques y agua, variedad de colinas y valles, que difícilmente pudiera imaginarse. Posiblemente el enemigo habría cruzado el río por aquí; pero era imposible vadear la corriente y dado que ellos habían llevado todas las canoas a la orilla opuesta, los intentos posteriores de perseguirlos resultaron infructuosos.

Me dirigí hacia la guardia con la intención de con-versar con los prisioneros, pero quedé escandalizado al enterarme de que habían sido muertos a bayonetazos por nuestras tropas en el camino, siguiendo órdenes del oficial que estaba a cargo de su custodia: el anciano fue muerto en seguida, el joven escapó con tres heridas de bayoneta en su cuerpo. Esta es la primera vez que nuestros propios soldados se vieron involucrados en el deliberado asesinato de sus prisioneros; ellos son sin duda tan bárbaros e insensibles como aquellos que llevan el nombre de Indios salvajes. Por la noche, una cantidad de fuegos atrajo mi atención y me encaminé hacia ellos para conocer su causa, encontrando a cada soldado provisto de una gran olla de barro en la que hervían guisantes y porotos y a varios ya borrachos: asombrado por el hecho, tuve deseos de saber cómo se habían procurado los utensilios y la bebida: mi sorpresa concluyó al enterarme de /491/ que cerca de nuestro campamento había un cementerio de los Indios, quienes, según su costumbre, entierran a cada difunto con sus utensilios domésticos, un talego de harina tostada y una jarra de chicha, que se conserva durante mucho tiempo, dado que la boca de la jarra se sella bien. Allí se habían procurado los soldados abundantes utensilios de cocina y la sidra con la que se embriagaron. Hice una visita a estos cementerios y encontré los cuerpos depositados en pequeñas canoas ubicadas generalmente en un foso cavado al costado de un declive. De acuerdo a sus nociones supersticiosas, los Indios creen que navegarán hacia el sol, de manera que sus canoas se fabrican cuidadosamente para que sean estancas. Se presta mucha atención a la preparación de la harina y de la chicha, pues se supone que tienen que durarles durante el viaje. Normalmente, cada hombre fabrica su propia canoa, de manera que mientras vive en este mundo la utiliza como arcón en su vivienda. Nuestra gente parecía desesperanzada por las pocas perspectivas de someter a los Indios o de aprender a Palacios o sus seguidores.

"Diciembre 25.- Temprano esta mañana la caballería fue enviada a forrajear. A las once, a. m., Calcaref (el viejo español, padre de Pedro Xaramilla ${ }^{21}$, ya mencionado) fue traído por los Indios. Lo encontraron a pie y solo. Parecía tener unos sesenta años de edad, sano y recio, con rasgos grandes que, aunque bastante pesados, revelaban inteligencia y astucia. Nos informó que los enemigos que atacamos el veintitrés eran unos 250 Indios, entre quienes estaba Palacios y sus seguidores; marchaban para dar un malón (un término Indio que significa sorpresa, saqueo y asesinato) /492/ a los Indios de Pitovquin, y cuando encontraron a nuestra vanguardia, se desmontaron para enfrentarla sin sospechar la proximidad del grueso de nuestras tropas. A raíz de ello, los Indios se dispersaron y él, que los acompañaba, fue sorprendido y capturado por nuestros Indios cuando trataba de regresar a su hogar. Dijo que Palacios y su familia se hallaban cerca de su casa y se ofreció a guiarnos hasta el lugar donde se refugiaban. En consecuencia, se despachó al Capitán Tupper con el viejo, llevando una fuerte partida con él. Sobre las cinco, p. m., fueron traídas tres mujeres jóvenes, dos de ellas las hijas de Calcaref; otra partida de caballería sorprendió a dos Indios y un muchacho español, aunque Palacios, que habría estado en su compañía en esta oportunidad, logró escapar: el muchacho fue enviado al campamento, y 
los pobres Indios fueron asesinados, como es usual. Se trajeron varias vacas lecheras con sus terneros: el pobre anciano derramó lágrimas cuando las vio, porque dijo que su familia dependía principalmente de ellas para su subsistencia.

“Diciembre 26.- El capitán L’Abbè recibió órdenes de avanzar con la caballería hacia Pucallan, situado más adelante a unas cuatro horas de marcha, donde se suponía que Palacios se había refugiado. Hacia las 2, p. m., regresaron el capitán Tupper y su partida luego de pasar la noche anterior en los bosques. Trajeron al hijo más joven de Calcaref en una litera: parecía tener unos veinte y cuatro años de edad, había estado afectado por una parálisis en sus extremidades inferiores durante algunos meses y aún continuaba indefenso: el cuidado y la atención verdaderamente impresionante que le prestaban su padre y hermanas ofrecía un con/493/ traste singular con la dureza y falta de sentimientos que había visto en todos los demás. A las cuatro, p. m., se ordenó que las tropas retrogradaran hacia Pitovquin. Mientras nos preparábamos para iniciar la marcha, escuché que algunos de nuestros oficiales superiores se quejaban al comandante de la división de que hubiera traído al más joven de los hijos de Calcaref en vez de haberlo eliminado a la bayoneta en los bosques, y se dio orden al oficial de guardia para que lo ejecutara durante la marcha de la tarde. Escandalizado por esta inhumanidad monstruosa, me determiné a usar toda estratagema posible para salvarlo. Por lo tanto, advertí secretamente a las jóvenes mujeres del peligro que amenazaba la vida de su hermano y les requerí vehementemente que no lo dejasen solo un momento, presumiendo que los bárbaros, aun salvajes como eran, no tendrían corazón como para matarlo en presencia de las mujeres. Durante la marcha, uno de nuestros jefes principales envío a alguien para ver si sus órdenes habían sido cumplidas y si no, para que se retirase a las mujeres. Me escabullí para ver a las muchachas, las aconsejé aún más fuertemente y ofrecí una excusa por ellas al comandante. Tuve el placer de ver que mi estratagema funcionó tan bien que todos llegaron a salvo al lugar de nuestro campamento.

"Diciembre 27.- Continuamos nuestra marcha placenteramente hacia Pitovquin; a lo largo de todo el camino, el terreno está cubierto con las fresas más deliciosas. Encontramos los cuerpos de los Indios que cayeron en la acción del 23 totalmente consumidos por los cóndores y otras aves de presa: solo quedaban los huesos como señal del sitio donde habían sido ultimados. Alcanzamos Pitovquin y acampamos cerca /494/ del lugar donde habíamos descansado el 21. Durante el día, nuestro prisionero enfermo era celosamente vigilado por sus hermanas para no dar ninguna oportunidad de que se ejecutaran las intenciones del comandante.

"Diciembre 28.- Hoy nos visitaron varios caciques y trajeron algunos bueyes como regalo.

El capitán L'Abbè se nos unió luego de su incursión en busca de Palacios: trajo consigo cuarenta y cinco novillos, quince potrillos y otros suministros. Describió el país en el que estuvo como mucho más rico y mucho mejor cultivado que cualquiera por el que hubiéramos pasado hasta el momento. Los aterrorizados Indios huyeron en todas las direcciones, abandonando su propiedad a merced de los destructores; jclemencia! iguay de ellos! no tuvieron ninguna: el pobre Indio fue cazado como una bestia de presa y muerto en el sitio donde se lo capturara. Sería lamentable que escapara un solo Indio que pudiera transmitir a sus compatriotas cuál era la causa de esta guerra exterminadora librada contra ellos -el crimen de apoyar a Palacios y sus seguidores. El joven Calcaref pareció mejorar durante su viaje y con la intención de dejarlo a salvo, lo informé al coronel, asegurándole que, bajo un cuidado apropiado, su salud se podría restablecer fácilmente; propuse que se lo enviara a Valdivia con sus hermanas. Me alegré de que esta 
propuesta fuese aceptada y permanecí feliz en la idea de haber sido útil en salvar la vida de una criatura sufriente. Nuestro objetivo ahora es cruzar el río (¿Toltén?) y penetrar en Borrea $^{22}$, país habi/495/ tado por una raza de Indios belicosos, cuyo aspecto y traza se dice que son similares a los de los europeos del norte. Esta fue la raza que mantuvo una furiosa guerra contra los españoles en el pasado, destruyendo las ciudades de Imperial y Villarica, matando a todos los varones y llevándose a las mujeres. Ya me he encontrado con varios Indios que encajan en esta descripción: sus rasgos recuerdan fuertemente a los de los Europeos y tienen una tez más sonrosada que las otras tribus, que les llaman Uingues $^{23}$, el mismo nombre que aplican a los Europeos. He preguntado a algunos de estos Uingues por una genealogía tradicional que pudiese arrojar luz sobre su origen, pero no he obtenido ninguna información. Esta tarde parte de nuestra compañía de granaderos pasó el río, preparando nuestro movimiento.

61 "Diciembre 29.- Una lluvia muy intensa cayó durante la noche y el tiempo todavía continúa nublado. Nuestras tropas cruzan el río tan lentamente que hicimos pocos progresos, pasando sólo sesenta hombres en el curso del día. El río tiene tres cuartos de milla de ancho y tenemos una sola canoa que con dificultad puede llevar a seis soldados y su equipo. Una vez apartada de la orilla, la canoa es arrastrada aguas abajo con gran rapidez, a pesar de los esfuerzos de cuatro Indios lozanos que, aunque utilizan sus remos para frenar la violencia de la corriente, no pueden impedir ser llevados a una milla del punto de partida. Por lo tanto, se pierde mucho tiempo remontando la canoa contra una corriente /496/ tan rápida; lo que se realiza a fuerza de caballos que la remolcan desde la ribera. Varias mujeres Indias visitaron nuestro campamento el día de hoy, trayendo frutillas, guisantes y piñones para vender. No pretendían dinero, preferían el trueque y la sal era muy apreciada. Todas estas mujeres estaban extremadamente sucias y parecían afectadas por sarna: su vestimenta es muy similar a la de los hombres, sólo que en lugar de un poncho llevan una pieza de tela de lana echada sobre el hombro derecho y pasada sobre el brazo izquierdo, de manera que exponen el hombro y parte del seno de aquel costado. El modo de adornar sus cabezas les da un aspecto muy ridículo, porque dividen su cabello, que es muy largo, en dos bandas, cada una de ellas trenzada y cubierta por una cinta, que luego de rodear la cabeza en direcciones opuestas, caen sobre una y otra oreja, de manera que parecen estar armadas con un par de cuernos, unos azules, otros rojos y algunos coloreados en parte, de acuerdo con el matiz de la cinta que adorna su cabello. Los frutos llamados piñones son del tamaño de las almendras y de forma parecida, pero mas curvados y angostos; están cubiertos con una cáscara al igual que la castaña, fruto a cuyo sabor recuerdan, especialmente cuando están hervidos o tostados. Sólo se encuentran en esta Cordillera y latitudes más meridionales y son el fruto de una especie de pino que, según se dice, crece hasta gran altura. ${ }^{24}$ Los pehuenches, una tribu vagabunda que habita la Cordillera /497/ e ignora el arte de cultivar la tierra, usa los piñones como sustituto del pan y las patatas: verdaderamente me parecieron un delicado componente de la dieta. Llovió durante el día entero y todos nosotros estábamos calados hasta los huesos.

62 "Diciembre 30.- El clima aún continúa muy desfavorable; con muchos problemas, pero sin ningún accidente serio, todas nuestras tropas cruzaron el río "Diciembre 31.- Llovió a cántaros durante toda la noche. El terreno en que hemos acampado es un simple banco de arena sin ninguna vegetación, a excepción de unos arbustos mal desarrollados; así que carecimos del menor reparo: en esta situación, nos alarmó el grito de ¡Los Indios! ¡Los Indios! Formamos con rapidez, pero afortunadamente se trató de una falsa alarma, 
porque si hubiera sido cierta nos hubiéramos encontrado en una situación complicada, dado que sólo un mosquete de cada diez estaba en condiciones de uso. Sobre el mediodía, el tiempo aclaró algo y luego de marchar media legua acampamos en una pequeña llanura protegida por cierta cantidad de grandes árboles. Varios caciques con sus séquitos, sumando en total unas 150 personas, nos hicieron una visita de homenaje y amistad: galoparon alrededor de nosotros varias veces, blandiendo sus espadas y haciendo un gran sonido ululante, al tiempo que se golpeaban repetidamente la boca con sus manos, aumentando de esta manera el estrépito de sus gritos: finalmente sofrenaron sus caballos enfrente de las tropas, que estaban formadas en línea para hacer una exhibición de fuerza tan grande como fuera posible; preguntaron si nuestras armas no habían sido dañadas por la lluvia y cuando la compañía de granaderos disparó sus fusiles hombre por hombre, lanzaron otro horrible /498/ grito de alegría. Los tambores y pífanos tocaron algunos aires vivos que los incitaron a realizar cabriolas extravagantes, presentando la apariencia más ridícula: habían llamado en su auxilio cada prenda de adorno que pudieron reunir vestían andrajosos uniformes españoles, gorras, sombreros con plumas, morriones, plumas, viejos cordones de oro y plata, etcétera, ostentados de la manera más irrisoria: era imposible contener una carcajada al presenciar esa extraordinaria exhibición.

"Enero 1, 1823. - El día comenzó con buen tiempo y después de una rápida inspección de nuestras armas, reiniciamos nuestra marcha. En el curso de dos horas, luego de subir una cuesta empinada, llegamos a una extensa llanura, tan plana como un campo de bolos. Allí nos esperaban unos 200 Indios. Se ordenó que las tropas se detuvieran, cuando los Indios se aproximaron y comenzaron a dar una larga perorata: presentaron varias demandas absurdas, más en procura de satisfacer venganzas privadas que en cumplimiento del objeto de la campaña, que por supuesto fueron rechazadas resueltamente por el coronel. Los Indios, aparentemente sorprendidos e irritados por el poco respeto concedido a su pretensión, comenzaron a hacer uso de un lenguaje amenazante y gestos hostiles: las tropas se formaron de inmediato en cuadro y el asunto pareció haber llegado a un punto extremo: sin embargo, los Indios, percibiendo la firme conducta del coronel, cedieron por último en todos los asuntos. Al mediodía, llegamos al final de la llanura e hicimos alto para almorzar en un huerto. Eran visibles en los alrededores los vestigios de recientes de/499/ vastaciones, se veían viviendas quemadas en todas las direcciones, cercas derribadas y huesos humanos esparcidos sobre el terreno, signos de una guerra devastadora. Habíamos llegado a las fronteras del país enemigo y nos proponíamos asolar su refugio esa noche. Durante la tarde atravesamos un bosque y cada pocos cientos de yardas nuestra marcha fue obstaculizada por barricadas levantadas con grandes árboles derribados y atravesados sobre el camino. Al ocaso, sorprendimos a dos mujeres y dos niños ocupados en recolectar frutillas; nos aseguraron que estábamos cerca del enemigo y nuestros Indios suplicaron al coronel que esperara hasta la próxima mañana. Después de una exploración adicional, resultó que aún nos hallábamos a una considerable distancia y proseguimos nuestra marcha. No obstante, los Indios avanzaban con un cuidado extremo que hacía suponer que nos enfrentaríamos con el enemigo a cada recodo del camino.

Cerca de las nueve de la noche detuvimos la marcha, debido al pedido urgente de los Indios; sin embargo, no se permitió prender fuegos y cada cuerpo estaba en alerta; imaginábamos escuchar a corta distancia un ladrido de perros y cacareo de gallos. A las 12 salió la luna, avanzamos nuevamente y en una hora llegamos a otra aldea desierta, de la que el enemigo se había retirado a un refugio que se encontraba a una legua y media de distancia: consiguientemente nos detuvimos en ella. 
"Enero 2.- Reiniciamos nuestra marcha al romper el día y después de avanzar una legua, nos vimos en la necesidad de dejar caballería y bagaje detrás de nosotros, debido a los obstáculos /500/ que oponían a nuestro progreso las numerosas barricadas, fosos y quebradas que encontrábamos. Caminando a veces y otras gateando sobre nuestras manos y rodillas, descubrimos en media hora las viviendas de los Indios que aún no sospechaban nuestra presencia. Sin embargo, pronto oímos resonar la alarma en toda la aldea que, seguida por los chillidos de las mujeres, anunciaba el terror de la gente; nuestras tropas se lanzaron en una carga, demasiado tardía para ganar la entrada, dado que su progreso se vio frenado por el malal, que es el nombre indio para su fortaleza, o refugio fortificado utilizado sólo en tiempo de peligro. Cada tribu posee un malal y en esta ocasión estaba construido sobre una eminencia, cuyo acceso había sido defendido por empalizadas de ocho a nueve pies de alto: estas cruzaban el camino que ascendía a la colina; estaban plantadas cerca unas de otras, con troneras a cada lado para la mosquetería: en el frente había un foso profundo y a ambos costados de la eminencia, un hondo precipicio que impedía toda aproximación. Detrás de la empalizada alcanzamos a distinguir Indios y Españoles que parecían decididos a resistir: en consecuencia se dieron órdenes de que avanzara la compañía de granaderos, pero el enemigo no esperó el ataque y huyeron después de descargar sus pocos mosquetes al azar; nuestras tropas perdieron algo de tiempo en escalar la empalizada; y después de una hora de cacería estéril, cesamos de perseguirlos debido a que estábamos muy agotados. Se enviaron pequeñas partidas a rastrear los bosques y luego de un rato reiniciamos nuestro avance. En ese momento, descubrimos que un hombre había sido herido por uno de los tiros disparados al azar desde el malal. Lo llevamos /501/ lejos, junto con varias mujeres y niños prisioneros, unas 300 ovejas, varios caballos, novillos, cerdos, etcétera. Se dio licencia a los soldados para matar y destruir cualquier bien del enemigo, y por consiguiente, a nuestro regreso al lugar donde dejamos la caballería, las viviendas, materiales e implementos de todo tipo habían sido incendiados y todas las plantaciones destruidas, cometiéndose los daños más perversos cada vez que surgía la oportunidad. Pequeñas partidas quedaron de guardia todo el día, algunas yendo, otras viniendo, llevando consigo mujeres, niños, bueyes, ovejas, etcétera; muchos indios fueron masacrados en los bosques. Nuestro campamento se abarrotó de ganado y parecía una gran feria: comenzaron a surgir serias reyertas sobre la división del botín; las mayores peleas se referían a mujeres y niños; por ello, fue necesario que se diera la orden de que todos los prisioneros y despojos debían estar a cargo de la guardia. Dos prisioneros traídos durante el día no fue-ron ejecutados, porque algunos de nuestros auxiliares los reclamaron como parientes. Dos mujeres y sus hijos fueron liberados e instruidos para que informaran a su cacique que si venía al campamento, se suspenderían las hostilidades en su contra; su persona y la de sus asistentes estarían a salvo y se le permitiría marcharse tan pronto como se llegara a un acuerdo.

"Enero 3.- Esta última noche, nos precipitamos en gran confusión debido a una falsa alarma ocasionada por el sargento de guardia, que disparó sobre uno de nuestros Indios dispersos, al que confundió con enemigos; su ejemplo fue seguido a lo largo de toda la línea y se requirió cierto tiempo para restaurar el orden. Hacia el mediodía el cacique /502/ Millan, confiando en las promesas del coronel, vino al campamento; parece un hombre maduro muy respetable y deseoso de acceder a todas las proposiciones que se le hicieron. Luego de prometer que regresaría en la mañana, fue despedido. 
"Enero 4.- El cacique Millan volvió temprano, trayendo consigo a varios ancianos, caciques e Indios de influencia en el distrito vecino, cada uno de los cuales, a su turno, dirigió al coronel un discurso elogioso. En esta ocasión, la edad parecía tener preferencia, porque aun cuando había entre ellos varios caciques de rango considerable, los ancianos siempre hablaban primero: sus discursos eran muy largos; no realizaban pausas ni buscaban las palabras; Tampoco hacían uso de ademanes, gesticulación o énfasis. Nuestros auxiliares Indios, que mantenían con nuestros visitantes una enemistad mor-tal, crearon cuanto obstáculo fue posible en el camino del acuerdo. Incluso le pidieron permiso al coronel para hacer una matanza con Millan y sus amigos; cuando la solicitud fue rechazada, rogaron con insistencia que se tolerara la inmolación de uno de ellos en homenaje al espíritu de uno de sus compañeros que Millan y sus aliados habían capturado a traición, simulando una negociación. A pesar de un firme rechazo y de la amenaza de inmediata represalia si se concretaba el menor intento en ese sentido, uno de los caciques que acompañaban a Millan fue apuñalado a traición durante la noche: aunque se realizó la más estricta investigación para identificar al perpetrador, resultó en vano. El acto, no obstante, fue muy aplaudido en el campamento de los Indios.

"Nada de particular ocurrió durante el resto /503/ de la campaña: se firmó un tratado con todos los Indios enemigos y nosotros volvimos sobre nuestros pasos camino a Valdivia, a donde llegamos el día 13. Los Indios se comprometieron a entregarnos a Palacios y a sus seguidores y permanecer en paz con sus vecinos patriotas, términos que han sido observados religiosamente."

\section{2) FELIÚ CRUZ, Guillermo. Memorias militares para servir a la Historia de la Independencia de Chile del Coronel Jorge Beauchef. Santiago de Chile, Ediciones Andrés Bello, 1964, 21 1- 219.} amigos a cumplimentarme en la misma pampa algunos llegaron art acompañarme; los admití. Luego estuvimos en Pitrufquén. obraban de buena fe; tenían agravios que vengar con los indios de Boroa, donde se habían retirado los montoneros de Palacios, luego que supieron mi entrada en la tierra de los indios. 
77 En aquel entonces yo tomaba todas las noticias posibles sobre la dirección que había seguido Palacios para ver el modo de apoderarme de él.

Estos indios me daban pocas esperanzas, o ninguna, por la inmensidad de las montañas de Boroa y la facilidad que tenían de esconderse en ellas.

Sin embargo, me decían, si podemos entrar en el Malal del cacique principal, que les ha dado refugio, se podría adelantar mucho y quizás al cacique a entregarlo.

Malal es nombre que dan los indios a un sitio fortificado por la naturaleza y que tiene sólo una entrada muy angosta.

Antes de pasar el río de Pitrufquen, grande y caudaloso y con pocos medios de atravesarlo, pregunté a los indios si más abajo había algún vado por donde los montoneros podían cruzarlo. Me contestaron que podían hacerlo a nado cuatro leguas más abajo, en el lugar llamado Donquil.

Resolví, entonces, mandar un fuerte destacamento a reconocer este camino antes de emprender el paso del río y evitar ser atacado en este acto que no podía efectuarse sin mucho desorden. Sólo tenía dos canoas de los indios, que podían llevar doce hombres en cada viaje, y todavía, dejando andar las canoas en la corriente y después tirarlas con caballos por ambos lados. Esta maniobra me debía tomar mucho tiempo, y como he dicho, ocasionar desorden. La caballada debía pasar a nado y las monturas en la canoa. Se organizó el destacamento y se puso a las órdenes del Mayor Rodríguez. Se componía de 100 granaderos al mando de Tupper y la compañía de caballería al mando del Capitán Labbé.

Todos los indios de Pitrufquén y más diez cazadores que se habían reunido de la compañía que tenía en el interior el cacique patriota Venancio Coñuepan formaban el resto. Estos cazadores se encontraban desde hacia mucho tiempo en la tierra de los indios y habían adoptado todas las costumbres de los salvajes. Sólo se diferenciaban de ellos en las armas, pues éstos cargaban tercerola y sable. De otro modo era imposible distinguirlos: vestido, idioma, pelo largo y suelto, tenían varias mujeres, en fin, iguales y se hallaban muy contentos con esta vida errante.

Los indios los apreciaban mucho por sus armas de fuego que mantenían con mucho cuidado. Vivían del pillaje y del botín que hacían entre los indios enemigos de la patria.

El Teniente de Cazadores Montero, hombre de mucha fama por su bravura, mandaba la compañía. Los cazadores y los indios de Pitrufquen se ofrecieron para formar la vanguardia y se pusieron en camino.

Yo me quedé en el campo con el resto de la infantería y algunos indios. A las pocas horas de haber salido recibí aviso del Mayor, en el cual me de/213/ cía que los indios de la vanguardia habían tenido un fuerte choque con los de Boroa, que los tenían todos al frente con Palacios y su montonera y que los socorriera.

Inmediatamente me puse en camino con el resto de la división.

Eran las cinco de la tarde cuando me encontré con algunos indios heridos y uno de los cazadores que tenía tres lanzazos en el cuerpo.

Este infeliz no se lamentaba de sus heridas, sino de la pérdida de su tercerola que los enemigos le habían quitado en la refriega. Fue indecible el contento de este hombre cuando le reemplacé su pérdida. Luego le pregunté lo que había sucedido. 
Estábamos caminando - me dijo - mi Coronel, delante con los indios de Pitrufquén, sin pensar en nada, cuando en un estrecho de la montaña nos hemos encontrado cara a cara con los indios de Boroa. Tampoco ellos nos habían sentido. Luego se armó una pelea muy fuerte, mientras avanzaba la infantería que estaba lejos. Habíamos adelantado demasiado y estábamos en derrota cuando llegó la infantería y reanudó el combate. Aquí se encontraba Palacios y él mandaba; pero nuestra gente marchó siempre adelante."

Oído este relato mandé curar por el cirujano de la división, que era don Tomás Leighton, inglés, a los heridos. Seguí marchando. Era ya de noche cuando llegue al lugar de la refriega.

Me fue imposible hacer avanzar a los indios que me guiaban, un paso adelante de los muertos que estaban allí. Es la costumbre, y tampoco les gusta caminar de noche. Me vi de este modo obligado a pasar la noche en aquel lugar.

\section{Al amanecer me puse otra vez en marcha.}

Tenía poco cuidado, pues no me había llegado otro aviso. Encontré en el camino treinta o cuarenta muertos. A las pocas horas estaba reunido con el destacamento cerca de un río. El Mayor no se había atrevido a cruzarlo.

Pocos instantes antes había aparecido Palacios al otro lado diciendo fanfarronadas.

Me dieron cuenta de la pérdida del Capitán de Artillería Arengreen, que había querido acompañarme con su amigo Tupper, lo que ocasionó un pesar general en la di-visión. Pero al poco rato, lo veíamos salir de la montaña en la cual se había escondido. Nos alegramos mucho de esta resurrección, pues muchos soldados decían haberlo visto lanceado. Nos dijo que, efectivamente, los indios le dispararon varios lanzazos. No lo hirieron gracias a que su buen caballo lo salvó, pudiendo ganar la montaña. Los indios no se atrevieron a seguirlo temiendo, sin duda, alguna emboscada de la infantería.

/214/ -"Ciertamente - continuó- he cometido una gran imprudencia adelantándome demasiado y casi me ha costado la vida. Aún no sabía cómo eran los indios."

8 Lo felicitamos y le recomendamos que otra vez no fuese tan imprudente. En realidad, hubiera sido una gran pérdida para el ejército. Se trataba de un distinguido oficial de artillería, muy instruido, de nacionalidad sueca que prestó muy buenos servicios a Chile siendo encargado de la maestranza.

9 Pasado el río, entramos en una pampa bastante grande. Un cabo que marchaba adelante con cuatro hombres, mató de un balazo, a mucha distancia, a un cacique que estaba revolviendo un buen caballo. Los otros al verlo caer, huyeron a rienda suelta. El cabo se apoderó del caballo y de todo el apero guarnecido de plata. Supimos después que era lo que llaman los indios un capitanejo y de los más valientes de Boroa.

Seguimos siempre adelante sin encontrar más que algunas mujeres, con sus hijos, escondidas en la montaña. Los indios de Pitrufquén las tomaban prisioneras. Eran de mucho precio para ellos. Llegamos a Donquil, pero ya los indios habían pasado al otro lado del río. Si el Mayor hubiese seguido adelante, cuando los encontró, habrían caído muchos al paso del río; pero tuvieron todo el día y la noche para atravesarlo sin apuro. Los que hubieran quedado a este lado habrían sido los de Palacios.

El Mayor creyó que tenían una gran emboscada juzgó prudente esperarme. Tuve que aprobarlo, pues los oficiales del destacamento querían seguir adelante y atacar.

Acampé en Donquil. Al momento mandé organizar partidas para recorrer la montaña. A las cinco llegó uno de los indios de Pitrufquén trayendo al lenguaraz Caleufo. Este se les 
presentó creyendo hablar con los indios de Palacios; como lo conocían, lo agarraron. La casualidad puso en mis manos la cabeza principal de la montonera, ya que los otros no eran nada sin él. El Gobernador de Valdivia le había hecho varias veces proposiciones muy ventajosas a este demonio, y nunca quiso admitirlas, sino hacer cuanto mal podía a la plaza. En el acto mandé traer la familia de este hombre, que estaba escondida en la montaña. Se componía de dos o tres hijas, bien bonitas, y un hombre. Este estaba enteramente tullido; otro encontrábase todavía preso en Valdivia. Llegaron después las partidas al mando del Capitán Labbé y Teniente Tupper: tomaron un muchacho que bebía agua en un estero y que servía a Palacios, el que estaba escondido muy cerca en la montaña. Al grito que dio el muchacho, cuando lo pescaron, huyó el facineroso, sin lo cual hubiera caído también.

Hice formar un Consejo de Guerra verbal para juzgar a Caleufo.

Fue sentenciado a la pena capital por traidor a la patria, acusado y confeso de varios homicidios. Ejecutado en el acto, su cabeza fue puesta en un palo plantado en el mismo lugar de su fusilamiento para servir de ejemplo a los demás.

/215/ Encontramos en Donquil todo lo necesario para la mantención de la división. Los animales vacunos que se hallaban en la montaña eran enormes; se puede decir sin exageración, eran casi el doble de los que generalmente se encuentran en la región.

Después de un día de descanso marché otra vez a Pitrufquén, pasando el río, y continué preocupándome de la acción de Boroa, felicitándome interiormente de haber mandado el destacamento a descubrir y reconocer el camino de Donquil. De este modo, evité una sorpresa y desconcerté enteramente el plan de los montoneros.

Consistía en atacarme al paso del río, encontrándome desprevenido y en desorden.

Capítulo LIV. La indiada amenaza la expedición cerca de Pitrufquen.

Al llegar a Pitrufquén, tuve noticia de que al otro lado del río se estaba reuniendo una gran indiada.

Al momento me dispuse a atravesarlo, lo que se efectuó en día y medio. Luego que la división estuvo reunida, acampada en una pampa, me anunciaron que dos caciques querían hablar conmigo. Di orden a la avanzada que los dejaran pasar.

112 Se me presentaron como amigos y solicitaron acompañarme en la maloca que yo iba a dar a los indios de Boroa, pues tenían sus agravios con éstos y todos los acompañantes eran indios patriotas, siendo la mayor parte de los pertenecientes a Venancio y Moquegua.

113 Efectivamente, los diez cazadores conocían a estos caciques. Les pregunté dónde estaban y cuántos venían. Me contestaron que venían como 800 y que estaban acampados muy cerca; que a mi primera jornada hacia Boroa se encontrarían conmigo en una pampa que había que atravesar.

114 Todo se convino con el Comisario don Luis Aburto.

115 A pesar de habérseme presentado como amigos, en estos caciques reconocía yo cuán frecuentes eran las traiciones de estos salvajes y no me fiaba enteramente de ellos; de modo que al entrar en la precitada pampa, mi división se encontraba formada en cuadro.

116 Apenas había dado algunos pasos cuando salieron de todas partes del bosque, a rienda suelta, gritando como si hubieran ido a atacarme. Habían tenido la precaución de dejar sus lanzas, de otro modo, los hubiera recibido con un rocío de balazos, no obstante la 
amistad que me habían ofrecido. Aparecie/216/ ron como unos 500 hombres, tan pronto como estuvieron a corta distancia de mis tropas, hicieron alto y se apearon los principales. Avanzaron como treinta pasos de mi cuadro y pidieron que fuese a hablar con ellos. Fui inmediatamente, acompañado del Comisario de Indios Aburto. Luego formaron círculo alrededor nuestro y empezaron su Parlamento.

Yo hacia un largo rato que estaba impacientado por sus griterías, cuando vi a Aburto mudar de semblante. Comprendí por el tono alto e imperioso que trataban de infundirnos miedo. Al instante, puse el sable en mano y a planazos deshice el círculo. Pegando a los más gritones, gané la columna y llamé al Comisario que estaba pálido como un muerto. Le ordené que les dijera que se marchasen y si no lo hacían los iba a exterminar a balazos. Luego cambiaron de tono y rogaron al Comisario que me sosegase y que harían lo que quisiera.

Yo estaba furioso por el atrevimiento de estos demonios. Pronto se me aproximó Aburto y le pregunté de qué trataban, para haber causado la alteración que noté en su semblante. Me contesto que efectivamente, los caciques nos amenazaban. Querían que disolviera mi división, tomar cada uno una parte de mis tropas, hacer la guerra como la entendían y me amenazaban con matarme allí mismo si no consentía.

Mi Comisario temblaba y decía que eran indios muy bravos. Me dieron ganas de reírme y se me quitó la cólera por la absurdidad de los salvajes.

¡Pretender intimidarme casi en medio de mis soldados!

500 a 600 hombres a caballo hacen mucho bulto, creyeron poder dictarme sus intenciones, pero se desengañaron muy pronto. $\mathrm{Al}$ fin, me hicieron tantas sumisiones que les permití acompañarme bajo la condición de que el primero que levantase la voz o faltase a mis órdenes sería fusilado.

El deseo de robar los hizo pasar por todo.

Sabían que los indios de Boroa tenían mucha hacienda y nunca habían podido entrar en su Malal.

Capítulo LV. La expedición consigue entrar al malal de Boroa. Se concluye la montonera del Norte de Valdivia y queda abierta la comunicación con la provincia de Concepción.

Continuamos adelante, sin fiarme mucho de los salvajes; pero mis precauciones fueron inútiles. Se portaron muy bien y me sirvieron de mucho, porque eran muy prácticos en esas inmensas montañas y en el Malal de Boroa.

Después de mil precauciones necias que acostumbran en sus guerras y que me hicieron observarlos, llegamos a un paso muy estrecho, luego a una que /217/ brada muy escabrosa llena de monte alto y al frente una palizada que tenía comunicación por un árbol cortado, al cual me acerqué con algunos granaderos.

En el acto recibí una descarga que hirió a dos de ellos. Saltamos encima del árbol y nos hicimos dueños de la palizada y del Malal. Penetraron los indios con nosotros. Serían unos cincuenta los que solicitaron acompañar la división a pie, porque no se podía penetrar a caballo.

Nos apoderamos de muchas mujeres y niños. Los indios enemigos huían al espesor de los bosques; mis soldados, divididos en pequeñas partidas, los perseguían en todas direcciones. Nos apoderamos de una gran cantidad de ganado lanar y vacuno de rara hermosura, algunos excelentes caballos, muchas yeguas, etc. 

que se quería de él. perdón. frioleras.

Establecí mi campamento en medio del malal, e hice recorrer la montaña por todos los puntos accesibles; pero sin fruto. Resolví llamar una india vieja, la bruja del cacique Melalican, principal cabeza de la indiada de Boroa.

En cuanto me la prestaron, le encargué que fuese de parte mía a ofrecer palabras de paz el cacique y que se presentase sin recelos a hablar conmigo. Que de este modo todos los niños y mujeres que estaban en mi poder, podrían cobrar su libertad; que también se le devolvería una parte de su hacienda, con la única condición de que me entregase a Palacios; que debía reconocer que, por causa de éste, había llegado la guerra a sus tierras; que tenía fuerzas para destruirlo si persistía en sostener a ese facineroso cobarde, el cual no sabía más que huir cuando se le presentaba el peligro y si no, que viese que entre los muertos en las dos refriegas, no había otros que sus propios indios.

Salió la vieja y en menos de dos horas estaba el cacique en mi presencia.

Me parecía incomprensible que este hombre y muchos otros que lo acompañaban, estuviesen ocultos casi en medio de mi tropa. Con seguridad se habrían dejado matar todas las mujeres antes de descubrir el lugar en donde aquéllos estaban ocultos. La fidelidad y castidad de estas mujeres es muy extraordinaria en medio de esta vida salvaje; no se abandonan ni a la fuerza ni al terror.

Apenas estuvo el cacique Melalican entre nosotros, cuando corrió hasta él un niño de 4 o 5 años, que se asió de sus piernas sin querer soltarlo, corriéndole las lágrimas de sus ojos; era su hijo. Este hombre se quedó parado con mucha dignidad, porque se creen superiores a nosotros. Esta escena me enterneció mucho.

4 Le entregué su niño sin condición alguna, acción de la cual me pareció muy agradecido. Lo convidé a sentarse a mi lado y se llamó al Comisario Aburto para que le explicara lo

Ya la vieja lo tenía prevenido.

A la proposición del Comisario de entregar a Palacios, respondió que los días anteriores se había separado de su indiada; que en absoluto sabía dónde se hallaba, pero que respondía llevárnoslo él mismo dentro de quin/218/ ce días a la plaza. Se le contestó que otras veces los in-dios nos habían engañado y que viera lo que hacía.

Volvió a repetir lo que había dicho y que cumpliría fielmente su palabra.

Entonces se le aseguró la paz.

En caso contrario pronto me tendría otra vez en su tierra y por aquel entonces no habría

A continuación fueron puestas en libertad todas las mujeres y todos los niños. Casi todos los oficiales tenían algunos.

Yo di el ejemplo: tenía una niñita que me había pedido mi querida Teresita. Hubo sus resentimientos entre los oficiales, pues las damas de la capital aprecian mucho las chinitas, que suelen ser muy buenas criadas; pero lo había prometido. Sólo tomé los animales necesarios para el regreso de mi división a Valdivia. Los demás, fueron entregados al cacique. Con todo, como acostumbran, al desaparecer al otro día, se llevaron los indios que me habían acompañado, muchas mujeres, niños y hacienda.

2 Propuse a los diez cazadores seguir en mi división. Sólo dos aceptaron, los demás se volvieron al Malal de Venancio. Les hice distribuir tabaco, papel, cartuchos y otras 
menor experiencia acerca de estas guerras. Pudo en aquel entonces, haber sido lastimada su filantropía; pero hoy día, que como profesional se ha establecido en el país y que ha adquirido la experiencia necesaria para emitir un juicio madurado largos años, y seguramente no escribiría de la misma manera en que lo hizo porque ha tenido ocasión de ver que la fi/219/ lantropía con estos salvajes es una candidez, por no decir una necedad. A pesar de todo, estaré con las posturas filantrópicas cuando no dañen la reputación ajena.

\section{3) TUPPER, William de Vic. Carta a Río de Janeiro a su hermano Ferdinand Brock Tupper Esq., fechada en Santiago de Chile, 4 octubre 1829, en TUPPER, Ferdinand B. 1972. Memorias del Coronel Tupper. Santiago de Chile, Editorial Francisco de Aguirre, 1972, 40-45.}

/40/ "En respuesta a algunas preguntas del hermano relativas a la narración hecha por el médico inglés Dr. Leighton, sobre /41/ una expedición en 1822 al territorio de los indios, publicada en Miers' travels in Chile, escribió desde Santiago en octubre de 1929:

153 Cerca de un mes antes de la expedición que Leighton narra, me envió el coronel Beauchef con treinta hombres a tratar de sorpren/42/ der a Palacios en su madriguera, situada en territorio indiano, distante a cuarenta o cincuenta leguas al norte de Valdivia.

La proyectada sorpresa fue planeada de acuerdo con la información prestada por un desertor, que había vivido algún tiempo /43/ con Palacios. Se ofreció para guiarme y aseguraba que podría ser alcanzado el escondite del bandolero en una sola noche. Nos aprontábamos para eso y, después de la más fatigosa marcha nocturna, llegamos al amanecer sólo a las fronteras del territorio /44/ de los indios de Toltén. Si tienes un buen mapa verás ese río hacia abajo. Eran tales indios amigos nuestros y me afirmaron que no alcanzaríamos el refugio de Palacios en menos de tres días de penosa marcha. 

comenzamos la expedición de la cual habla Leighton Yo iba con la división que, al mando del mayor Rodríguez, fue enviada contra Palacios. Divisamos al enemigo en medio del camino y después de una pequeña escaramuza lo hicimos huir. Perdieron seis hombres y nosotros tuvimos sólo dos o tres heridos. Rodríguez se comportó de la manera más cobarde, pues debíamos haber manejado a los indios con más rudeza. Cuando nos atacaron nos estábamos refrescando en la orilla de un hermoso río, el Pitrufquén o Toltén. Es el mismo río, pero que se denomina distinto en diferentes partes; forma la frontera entre la provincia de Concepción y Valdivia. Inmediatamente después de la lucha propuse continuar nuestra marcha hacia el norte a través del paraje más hermoso que yo nunca he visto en mi vida. Un día, estando yo en la avanzada de la división, como a media legua, con 16 infantes, espié a una vieja mujer indígena recogiendo habas en un campo. La sorprendí junto a un niño y, a través del intérprete, le pregunté por el resto de su gente (Los indios, cuando son invadidos, tienen el hábito de ocultarse en lo más recóndito de los bosques). Ella estuvo muy obstinada, pero un pequeño pinchazo de bayoneta la puso razonable. La acompañé con seis de mis hombres, atravesando junglas y bosques casi impenetrables, al menos por dos o tres leguas. En definitiva llegué a convencerme de que estaba jugando conmigo y fui obligado a recurrí a otros argumentos más prácticos. Nos condujo entonces muy quieta hacia el escondite de los suyos. Arribamos completamente desapercibidos por estos. Los indios, situados en círculo en un lugar que habían 
despejado, eran unos diez o doce hombres y como otras tantas mujeres y niños. Estaban hablando en voz muy alta, como es usual entre ellos. Ordené a mi gente que apuntaran sus armas y yo dirigí mi rifle (uno que me dio Elisha Tupper) contra un hombre que aparentaba ser más bien el jefe de todos. Cuando estaba a punto de disparar el gatillo el /42/ hombre tomó un niño en sus brazos, en tal posición que resultaba casi imposible abatirlo a él solo, por lo cual, en vez de exterminarlos, ordené a mis hombres que se precipitaran cerca de ellos. No pueden imaginarse el grito aterrado que dieron. No ofrecieron resistencia pero huyeron en la más grande confusión. Sólo apresamos a cinco de ellos, fuera de todas las mujeres y niños. Los conduje a la división. Los varones fueron enviados inmediatamente a retaguardia y atravesados a la bayoneta por la escolta. Llevé lejos de eso a las mujeres y niños. Algunos de nuestra tropa y otros, simpatizantes de los indios, se reservaron unos pocos niños y niñas de unos seis años para conducirlos a Santiago, donde son muy apreciados como sirvientes. Todos ellos lamentaron su suerte en llantos muy ruidosos, pero estaban pasablemente resignados en pocos días.

“Todo esto -sigue diciendo Tupper a su hermano- te parecerá monstruosamente cruel, pero debes recordar que las guerras con los indios se reducen siempre a exterminaciones; los indios nunca dan cuartel, y, en consecuencia, es muy raro que dejen con vida a un hombre blanco que haya caído en su poder. Su modo de ejecutar es este: sostienen al prisionero rígido, completamente desnudo, y lo ubican en un círculo formado por indios a caballo. El jefe entonces galopa y lo coge con la punta de la lanza, arrastrándolo por algunos segundos, teniendo cuidado de no herirlo en alguna parte vital. Esta operación es repetida por todos los caballeros presentes (gentlemen present, sic) hasta que su víctima es atravesada en un lugar importante. Tal es el trato que esperamos recibir de los indios. Pensarás, sin embargo, que si el hombre blanco diera un ejemplo de moderación estos salvajes lo comprenderían. Siempre se ha tratado de hacer eso y nunca con resultados positivos. No es posible concebir lo brutos y traidores que son y cómo están horriblemente desposeídos de todo sentimiento de humanidad. En verdad, la conducta de los hombres blancos hacia ellos es, por lo general, muy cuidadosa y acompañada de mucha moderación. Los blancos tienen muchas cosas que perder en una guerra con los indios, y éstos muchas que ganar en una guerra con los blancos. Por consecuencia las agresiones vienen casi sin excepción de los indios. Los aborígenes del Sur de Chile poseen una gran fuerza muscular y son muy valientes: son excesivamente flojos y realizan poco, pero cabalgan y combaten.

161 /43/ "Viven en las mejores chozas que pueden construir -sigue diciendo más adelante el coronel Tupper a su hermano Ferdinand-, pero nadan en la inmundicia y pocos son los que no tienen sarna. En verdad, tus filósofos pueden hacer bulla en torno a la inocencia y belleza de la vida salvaje, pero eso no disminuye su real desagrado y brutalidad.

"Para concluir esta cansadora narración, diré que después atacamos el Malal o el refugio del cacique Millian $\mathrm{y}$, con pocas probabilidades, nos hicimos dueños de él. Allí encontramos cien cabezas de ganado vacuno y unas mil ovejas, de las cuales comimos en abundancia. Al poco tiempo Caleufo fue tomado prisionero. Fui enviado con él en busca de su familia y, aparte de listo hijo citado por Leighton, hice prisioneras entre su tribu a hijas muy bonitas, las que lucían decentes. Estuve bastante estúpido en relación a las heroínas de mi historia, no siendo particularmente respetables; de hecho, fuí más tarde informado por los oficiales que a estas princesas (princesses, sic) les habían sucedido las cosas más indecentes en la tienda del coronel y los mayores, durante todas esas noches. El joven hijo de Caleufo era llevado por nosotros en una litera, pues pretendía sufrir los efectos de un 
ataque de parálisis, y te puedo asegurar que no lo atravesé a la bayoneta en el bosque solamente porque esperaba de él una información referente a Palacios. Por eso no merezco el elogio que Leighton indirectamente me confiere. Lo cierto es que ese bribón de indio estaba sólo aparentan-do; al poco tiempo después de llegar a Valdivia la guardia estaba distraída cuando él tomo por sus propios pies la senda del río y de la montaña. Fue muerto antes de que hiciera más daño.

El viejo Caleufo -sigue narrando Tupper- fue fusilado al llegar a Valdivia. Era un lenguaraz o intérprete y Capitán de Indios (palabras en castellano en el original) en las fuerzas de España, país al cual continuó fiel. Creo que había nacido en Valdivia; era un hombre blanco, excesivamente bravo e intrépido. Trasladó a su familia entera dentro del territorio indígena cuando los realistas fueron expulsados de Valdivia (por Lord Cochrane en 1820) y mantuvo una cruel guerra contra los patriotas, hasta el momento de su muerte.

"El Coronel Beauchef, después de imponerles castigos sumarios a los más rebeldes, llamó a todos los caciques del sur del río Imperial a juntarse en una asamblea y acordó una paz general. Desde entonces las comunicaciones para el correo están abiertas entre Concepción y /44/ Valdivia, permaneciendo los indios atemorizados por nuestra fuerza. Durante todo esto la conducta del coronel Beauchef fue merecedora de los más altos elogios, no obstante lo cual, la sensibilidad del doctor Leighton pudo ocasionalmente ser herida. La división retornó a Valdivia después de pasar en el territorio indígena durante un mes" (Según carta original que pertenece a la colección del señor Manuel Bianchi, citada en la Bibliografía de este volumen).

\section{4) MEMORIAS DEL CAPITÁN DON JOSÉ VERDUGO (Archivo Nacional de Santiago de Chile, Fondo Vicuña Mackenna, Volumen 139, fojas 36 recta a 37 vuelta).}

/Fojas 36 recta/ En el mes de Diciembre del mismo año de 822. Oficio el Coronel Beauchefe [...] si nuestra compañia estava lista para espedicionar ala tierra delos Araucanos en perseguimiento del Bandido Palacio Jefe de una division de Godos malvados y asesinos que se hallaban entre los Yndios, y al mismo tiempo ordeno el Governador dela Ciudad de Osorno pusiese 500 Yndios Guilliches para marchar con nosotros; salimos en el mismo mes de Disiembre con 112 hombres que tenia nuestra Compañia, mas 50 milicianos, y como 600 Yndios boluntarios que se ofrecieron a venir muchos mas, y todos mui patriotas. Como en aquella prov. ${ }^{\text {a }}$ llueve hasta en verano los aguaseros nos ysieron demorar mas de 20 dias para llegar al punto de San Jose donde nos haviamos de reunir con la fuerza de Ynfanteria que salida de la plaza de Valdivia con el Coronel Beauchefe, alos 4 dias de estar en San Jose, llego la fuerza de ynfanteria que se componia serca de mil hombres; y rreunidos ya todos seguimos la marcha introdusiendonos en la tierra de los Araucanos, llegamos al lugar de pituquen, y al otro dia sorprendi-mos un campo de yndios Enemigos que venian con la yntencion de asaltarnos en la noche donde estavamos acampados, mas como ese dia haviamos emprendido la marcha nos fuimos a encontrar como a las dose del dia donde los batimos muriendo bastante de ellos, y los de-mas escaparon al monte; seguimos despues de esto la marcha hasta que nos alojamos, aquella noche no nos dejaron dormir por que toda ella se pasaron los Enemi-gos tirandonos tiros y los Yndios con sus alaridos en forma de pegar la carga, segun cos/fojas 36 vuelta/ tumbre de ellos. Al otro dia quedo nuestro campamento en el mismo punto, y nombraron 
ami Cap. ${ }^{\mathrm{n}}$ con toda nuestra Compañia para marchar almalal de Palacio, caminamos y como alas cinco del dia llegamos á el y como conmigo harian tres dias havia tenido un disgusto quiso bengarse con migo en aquel momento, y me ordeno que escogiese 25 soldados; para que dentrase adentro del malal yo le contes ${ }^{25}$ que no tenia que escoger pues todos para mi eran buenos, entonse[s] me contest. ${ }^{\text {to }}$ el tome los que guste, entonse[s] di la orden saliesen 25 soldados de la derecha, ami bos salio toda la comp. ${ }^{\text {a }}$ (esto lo hasian por que yo era para con mis soldados mui estimado) entonse[s] tuve que nombrarlos uno auno y cuando estavan listo[s], me ordeno mi Cap. ${ }^{\mathrm{n}}$ dejase los sables y que llevase solo caravinas, y seme dio un soldado que delos enemigo[s] se havia pasado a nosotros, y este era muy baquiano, dentramos al monte apie pues acavallo no havia dentra-da por aquel punto, y luego que pase con mi tropa un rio Ancho, por en sima de un arvol boltiado y que atravesava de un lado a otro, me dijo el baquiano me quedase alli mientra el yva a espiar al enemigo asegurandome que no havia media cuadra donde devian estar los cuarteles fue ynmediatamente volvio y entonse[s] abanse yo con mi tropa siempre por el bosque, y al concluir este havia una pampa corta y ala orilla estavan las ramadas de sus cuarteles, me aprosime yo vien a ellos como a 20 pasos y los beo que estan ocupados en aser sus almuersos ala orilla de los fogones, dispuse mis 25 soldados vien ordenados mande preparar y apuntar muien secreto, y la voz de fuego, la di en toda la fuerza de mi vos, yse [in]mediatamente la de carga; el enemigo arranco inmediatamente al bosque pues estava serca, como la descarga que yse aser fue tan serca, ylos enemigo serian cuando mas unos 40 , y se hallaban rodiados a cinco fo-gones, en yleras en que estavan asiendo sus asados, yollas de Guisos, nose perdieron balas muchas por que de la descarga quedaron 14 muertos y 7 mal heridos, y en los que arrancaron al monte no dejarian de ir algunos herido[s], y muchos mas ubiera pillado pero mis soldados seme entretuvieron en el despojo de las monturas de los Enemigos, y de los mui buenos asados que hacian, y como estavan contanta nesesidad, me costo usar del rigor del sable para aserlos que cogiesen sus armas y abansasen, y como no llevavan mas Arma que las Caravinas, era preciso aserlos cargar, y despues abanse al Bosque, llevar sus asados y comiendo sobre la marcha; yno haviendo en contrado ya enemigo ninguno; en contre muchas Bacas y mantas; entonse sali del Bosque ymande el parte al Cap. ${ }^{\mathrm{n}}$ y que me mandara los cavallos para llevar un piño de Bacas, que adistansia de doce cuadras mas arriva havia dentrada para Cavallos, al malar; luego el Cap. ${ }^{\mathrm{n}}$ como estava serca por el punto donde ya havia dentrado a pie, tuvo la notisia, y me mando los Cavallos; y en cuanto yse montar a mi tropa, comense a rrodiar Bacas y sali afuera con 86 de ellas, mis soldados hallaron un buen votin de 7 cargas de petacas, llenas con ropa de toda laya, y muchas alhajas de plata y oro y monturas mui antiguas chapiados con plata y con 6 pares de charreteras, divisas militares, de todo lo que era ropa y cosas de monturas, y mantas las repartio el cap. ${ }^{\mathrm{n}}$ entre la tropa; y los prendas de plata, como ser fuentes, platos Bandejas, cuviertos con cucharas, ma-/fojas 37 recta/ tes, saumadores, espuelas y otras prendas mas que no hago mencion, los tomo el prometiendo a la tropa que con aquella les yva aser un bestuario, lo que no se vio nunca. Concluido todo esto marchamos a rreunirnos con el Ejercito llevando la banda de cornetas monturas, chapia-dos con plata, una charretela de plata puesta en la frente de sus cavallos, y las 86 Reses que sirvieron al ejercito mui atiempo por que tenia mucha necesidad de ellas, y tan pronto que llegamos al ejersito que serian las 2 de la tarde se comensaron a matar Bacas, y hasi que la tropa comio, me mandaron para que marchase al lugar de pocoyan, dandome 50 soldados de mi compañia y 25 soldados de Ynfanteria, al mando de su Alferes Solis, dandome por vaquiano al soldado que se havia pasado del enemigo a nosotros; camine dos dias suviendo unas montañas ynmensas, sin haver en 
contrado una pampa ni de $2 \mathrm{v}^{\text {as }}$ donde alojar de noche, el terser dia camine abajar la Cordillera y cuando yvamos allegar me dijo el soldado Guia, Señor aqui en este lugar hay mas de dos mil Yndios, y lleva V mui poca fuerza, en fin bajamos al dicho lugar, que es una pampa mui larga y mui vonita, porun lado la sircula un Rio caudaloso, por otro una Cordillera mui alta. En cuanto baje ya abajo se presentaron como 300 Yndios, pero como yo ynmediatamente tome la posesion de bajo de un mansanal no pudieron descuvrir la fuerza, y cuando ellos se allegaron los 25 Ynfantes rompieron fuego, y los Yndios bolvieron cara y entones los Carge yo con mi Cavalleria; y como la noche ya serro escaparon todos al monte, entonse comense arrodiar Caballos, Bacas y ganado obejano, y ha eso de las dies de la noche me vine arreunir conla Ynfanteria, y la pase toda la noche sobre las Armas, a causa que algunos tiros que venian a tirarnos algunos Españoles, que andavanse con ellos. Al otro dia me encuentro con 250 Bacas, y con 60 Cavallos de lo mejor que alli hay, con mas de 14.mil obejas las que havia yntentando de aserlas degollar por no poder marchar con ellas, a Causa de la cierra que tenia que pasar, pero determine dejarlas y marche con las Bacas y Cavallos; a los 3 dias en la noche vine adar al punto donde havia dejado el ejercito cuando seme havia dado la Comision, y no haviendole encontrado alli, tuve que alojarme en el mismo punto; esa noche me llovio mucho, ytuve que pasar parado con toda mi tropa en formacion con las Armas en la mano y mi ganado de presa arreta guardia y ala orilla de un Rio, pues el enemigo no seso toda la noche estar tirando sus tiros, y dando los gritos, me mataron un soldado yme yrieron 3 ylos que resivieron mas valas fueron las Vacas, y los cavallos, pues la noche estava mui obcura y un temporal, mui grande y por eso no alcansavan a ver mi formacion, y tambien porque yo no quise tirarles un solo tiro, y esperava que se me asercasen vien para aser mis fuegos. En cuanto aclaro, el Enemigo no paresio a incomodarme, pero yo me hallava todo confuso, sin poder discurrir para donde tomaria pues no savia que diresion habia tomado el ejercito, ni podia tomar Guella alguna por lo mucho que havia llovido en la noche; y que el Jefe del ejercito no ubiera sido /fojas 37 vuelta/ para mandar-me un propio avisandome para donde haria su marcha, en este apuro me consulte con el soldado baquiano, y este dijo que talves ubiese tomado el ejercito por pituquen; tome pues esta direcion, $\mathrm{y}$ alos tres dias llegue a Tolten donde allo al ejercito que estava pasando el Rio, y luego me fui ami Compañia donde estava mi Cap. ${ }^{\mathrm{n}}$ aquien hasiendole los cargos por no haverme mandado ningun conosimiento de la direcion que havia tomado el ejercito; este me contesto que un Yndio havia venido a decir al Jefe que yo havia sido batido por los Yndios de pocoyan y que todos haviamos peresido sin escapar uno, y que el Jefe viendo que yo me dilatava le avia creido. Mi llegada al ejercito alegro mucho tanto porque todos ya me consideravan perdido como por la mucha Cavallada que llebava, y mayormente las 248 Bacas que lleva [va] pues de las primeras ya no les quedaba mas que por ese dia. Como el ejercito estava la mayor parte de otra banda del Rio, estava tamvien el Jefe, tube que yr adar cuenta de mi comision, este me resivio mui vien disiendome ya no esperava verlo a V. mas pues tuve notisias mui siertas de haver peresido V. y toda su tropa. En dos dias paso todo el ejercito el Rio pues lo berificamos en canoas mui pequeñas y el Rio alli es grande y correntoso, y ancho, Cuando ya estuvo todo el ejercito al otro lado del Rio ypuesto en orden para su marcha, y formado en Batalla fuimos rodiados de un campo de Yndios de mas de 5000, que en el medio de un llano nos hecharon al medio: para asernos honores (pues eran Yndios amigos) segun costumbre de ellos; sin embargo nosotros estavamos reselosos, y cuando se retiraron como cuatro cuadras de nosotros, y volvieron formandose como para darnos un Carga, mi Cap. ${ }^{\mathrm{n}}$ se haserco ami y me dijo, mi teniente, si en algo le he ofendido perdoneme por dios, pues aqui todos bamos a ser victima[s], no ve V. como la yndiada se 
han divido al frente retaguardia a derecha, ysquierda, y senos ban a benir ala Carga, esto me estava diciendo mi Cap. ${ }^{\mathrm{n}}$ cuando soltaron un grande grito en una vos toda la Yndiada, y enseguida, se viene asi a nosotros con sus lansas en Ristradas, formando un ruido espantoso, y una griteria horrorosa, pero al llegar sobre nuestras filas bolvieron cara con mucha prontitud, y bolbieron a cargar el campo, dejandonos a nosotros en la obscuridad del polvo, siendo esta una costumbre que ellos tienen en seña de honor, y el gusto que manifiestan por hallarse con Jentes amiga.

Concluida[s] las seremonias de los indios, marchamos en derechura al malal de Guiliqui que era donde tenian gana los Yndios de entrar, pues no lo havian podido aser por que en dho malal havia mucha yndiada, godos y amas havian como 400 hombres de fusil, y al otro dia llegamos, y todas las yndiadas nuestras rodiaron la montaña y mi compañia de cavalleria tambien, y el Coronel Bauchefe dentro conla Ynfanteria adentro, que despues de un vivo fuego se tomo el malal, con algunos pricioneros y todos los demas sefueron a los bosques, y el malal quedo entregado a los Yndios de boroa que ally yban con nosotros, trayendo nuestro ejercito para la plaza de Vald. ${ }^{a}$ y haviendo llegado al lugar de San Jose la Ynfanteria se embarco para Valdivia, yami seme destino con mi Comp. ${ }^{a}$ y los Yndios Guilliches para la Ciudad de Osorno, y mi Cap. ${ }^{\mathrm{n}}$ sevino a Vald. ${ }^{\mathrm{a}} \mathrm{y}$ yo llegue a Osorno alos 20 dias de marcha, porlo mucho que nos llobio en todo el Camino.

\section{BIBLIOGRAPHY}

Barros Arana, D. (1897). Historia Jeneral de Chile (Tomo XV). Santiago: Josefina M. De Palacios Editora.

Barros Arana, D. (1902). Historia Jeneral de Chile (Tomo XVI). Santiago de Chile: Imprenta Cervantes.

Barta, T. (2005). Mr. Darwin's shooters: on natural selection and the naturalizing of genocide. Patterns of Prejudice, 39 (2), 116-137.

Brantlinger, P. (2003). Dark vanishings: discourse on the extinction of primitive races, 1800 -1930. Ithaca \& London: Cornell University Press.

Bustamante, J. J. de. (1902 [1835]). Memoria que el Ministro de Estado en el Departamento de Guerra $i$ Marina Presenta al Congreso Nacional. Año de 1835. En Valentín Letelier (editor), Sesiones de los Cuerpos Lejislativos de Chile (Tomo XXIII, 1834-1836, pp. 441-472). Santiago de Chile: Imprenta Cervantes.

Cruz-Coke Madrid, R. (1995). Historia de la Medicina Chilena. Santiago de Chile: Ediciones Andrés Bello.

Darwin, C. (1839). Journal and Remarks. En Narrative of the Surveying Voyages of His Majesty's Ships Adventure and Beagle between the years 1826 and 1836 (Volume III). London: Henry Colbourn.

Dwyer, P. G. (2009). It Still Makes Me Shudder: Memories of Massacres and Atrocities during the Revolutionary and Napoleonic Wars. War in History, 16 (4), 381-405. 
Dwyer, P. G. \& Ryan, L. (2012). Introduction: The massacre in history. En P. G. Dwyer \& L. Ryan (eds.), Theaters of Violence: Massacres, Mass Killing and Atrocity throughout History (pp. XI-XXV). New York: Berghahn Books.

Feliú Cruz, G. (1964). Memorias militares para servir a la historia de la Independencia de Chile del Coronel Jorge Beauchef, 1817-1829. Santiago de Chile: Editorial Andrés Bello.

Ferguson, R. B. \& Whitehead, N. L. (1992). The Violent Edge of the Empire. En R. B. Ferguson \& N. L. White-head (Eds.), War in the Tribal Zone: Expanding States and Indigenous Warfare (pp. 1-30). Santa Fe: School of American Research Press.

Figueroa, P. P. (1900). Diccionario Biográfico de Estranjeros en Chile. Santiago: Imprenta Moderna. Goldhagen, D. J. (2010). Peor que la guerra. Genocidio, eliminacionismo y la continua agresión contra la humanidad. Madrid: Taurus.

Harrison, S. (2008). Skulls and scientific collecting in the Victorian military: Keeping the enemy dead in British frontier Warfare. Comparative Studies in Society and History, 50 (1), Lugar. Editorial, 285-303.

Howard, M., Andreopoulos, G. J. \& Schulman, M. R. (eds.) (1994). The Laws of War: Constraints on Warfare in the Western World. New Heaven \& London: Yale University Press.

Howard, M. (1994). Constraints on Warfare. En Howard, Andreopoulos \& Schulman (Eds.), The Laws of War: Constraints on Warfare in the Western World (pp. 1-11). New Heaven \& London: Yale University Press.

Humphrey, M. (2002). The politics of atrocity and reconciliation: from terror to trauma. London/New York: Routledge, Taylor \& Francis Group.

Jones, K. (1986). Nineteenth-Century Travel Accounts of Argentina. Ethnohistory, 32 (2), 195-211.

Keeley, L. H. (1996). War before Civilization. Oxford/New York: Oxford University Press.

Leighton, T. (1826). Journal of a Military Expedition into the Indian Territory. En John Miers, Travels in Chile and La Plata including accounts Respecting the Geography, Geology, Statistics, Government, Finances, Agriculture, Manners and Customs (Volume II, pp. 472-503). Lon-don: Baldwin, Cradock \& Joy.

Lemkin, R. (2005). Tasmania. Patterns of Prejudice, 39 (2), 170-196.

Levene, M. (1999). Introduction. En M. Levene \& P. Roberts (eds.), The Massacre in History (pp. 1-38). New York/Oxford: Berghahn Books.

Ober, J. (1994). The Classical Greek Times. En Howard, Andreopoulos \& Schulman (Eds.), The Laws of War: Constraints on Warfare in the Western World (pp. 12-26). New Heaven \& London: Yale University Press.

Pagden, A. (1988). La caída del hombre natural. El indio americano y los orígenes de la etnología comparativa. Madrid: Alianza Editorial.

Parker, G. (1994). Early Modern Europe. En Howard, Andreopoulos \& Schulman (Eds.), The Laws of War: Constraints on Warfare in the Western World (pp. 40-58). New Heaven \& London: Yale University Press.

Pinto Rodríguez, J. (1996). Integración y desintegración de un espacio fronterizo. La Araucanía y las Pampas, 1550-1900. En J. Pinto Rodríguez (ed.), Araucanía y las Pampas. Un mundo fronterizo en América del Sur (pp. 11-46). Temuco: Ediciones Universidad de la Frontera. 
Pratt, M. L. (1997). Ojos imperiales: Literatura de viajes y transculturación. Quilmes: Universidad Nacional de Quilmes.

Stacey, R. C. (1994). The Age of Chivalry. En Howard, Andreopoulos \& Schulman (eds.), The Laws of War: Constraints on Warfare in the Western World (pp. 27-39). New Heaven \& London: Yale University Press.

Trouillot, M.-R. (1995). Silencing the Past: Power and the Production of History. Boston: Beacon Press. Tupper, F. V. (1972). Memorias del coronel Tupper (1800-1830). Buenos Aires: Editorial Francisco de Aguirre.

Vattel, E. de. (1834). El Derecho de Gentes, ó Principios de la Ley Natural, aplicados a la conducta, y a los negocios de las naciones y de los soberanos (Tomo II). Madrid: Imprenta de D. León Amarita.

Vicuña Mackenna, B. (1868). La Guerra a Muerte. Memoria sobre las ultimas campañas de la Independencia de Chile, 1819-1824. Santiago de Chile: Imprenta Nacional.

\section{NOTES}

1. Silent enim leges inter arma.

2. En esta nota y las inmediatamente sucesivas, remitiremos la atención del lector a la información contenida en las fuentes ubicadas más adelante. En todos los casos, la paginación o la foliatura son las que corresponden originariamente a esos textos. Con respecto a la vida de los no beligerantes, ver Leighton, 1826, p. 480; y a su honra y afectos, Tupper, 1972, pp. 43, 44 (nota al pie).

3. Leighton, 1826, p. 501; Feliú Cruz, 1964, pp. 217, 218; Tupper, 1972, p. 42 (nota al pie).

4. Tupper, 1972 , p. 40 (en la nota al pie).

5. Leighton, 1826, p. 487.

6. Leighton, 1826, pp. 487-488, 489, 490, 492, 493; Feliú Cruz, 1964, p. 214; Tupper, 1972, pp. 42, 43 (en la nota al pie).

7. Leighton, 1826, p. 501; Feliú Cruz, 1964, pp. 212, 214, 217, 218; Tupper, 1972, p. 43 (nota al pie); Verdugo, fojas 36 vuelta, fojas 37 recta.

8. Leighton, 1826 , pp. 475,501

9. Leighton, 1826, p. 491.

10. En realidad, se seleccionaron los fragmentos pertinentes de las memorias de Beauchef Isnel (Feliú Cruz, 1964) y de los escritos reunidos por Ferdinand Brock Tupper, hermano mayor del capitán Tupper Brock (Tupper, 1972). Ambas publicaciones están hoy agotadas, lo que dificulta el acceso a ellas. El diario de Leighton (en Miers, 1826-2, pp. 472-503) fue traducido para esta presentación por uno de nosotros (Juan Francisco Jiménez) y hasta donde sabemos es la primera vez que se publica en castellano: en este caso, optamos por reproducirlo en su totalidad, debido a que también incluye material valioso acerca de los modos de vida y de las prácticas bélicas indígenas. Asimismo, las reminiscencias de José Verdugo se incorporaron íntegramente, dada su brevedad.

11. Otro inglés, Charles Darwin, también fue testigo de la similar conducta del ejército en campaña contra los indios de las pampas, pocos años despues de concluida en Chile la Guerra a Muerte. Mientras esperaba en Bahía Blanca el arribo del Beagle -agosto de 1833-, escuchó sombríos relatos acerca del trato que recibían los prisioneros -cruelmente torturados para obtener información- y tuvo además la oportunidad de constatar que las mujeres nativas en edad reproductiva eran habitualmente pasadas a degüello por los soldados: "When I exclaimed that this appeared rather inhuman, he answered, 'Why, what can be done? They breed so!' ". Al ver que nadie 
cuestionaba estos métodos, consignó en su diario una crítica airada: "Every one here is fully convinced that this is the most just war because it is against barbarians. Who would believe in this age, in a Christian civilized country, that such atrocities were committed? (Darwin, 1833, p. 120). Sin embargo, más adelante reaccionaría de manera distinta. En febrero de 1836, su visita a Tasmania coincidió con incursiones de análogas características, durante las cuales se perpetraron toda clase de atrocidades para exterminar a los aborígenes de la isla, tales como perseguirlos y acosarlos con perros rastreadores o suministrarles alimentos envenenados. No obstante, el tono de indignación moral que le había provocado el accionar de aquel ejército de bandidos, mestizos y mulatos en el sur de Buenos Aires fue ostensiblemente sustituido por otro más neutro, con el que se refiere al inevitable límite que, dejando de lado las previas conductas violentas de algunos de sus propios compatriotas instalados en el lugar, debió ponerse a una sucesión de robos, incendios y muertes "committed by the blacks": en este caso, la magnitud de los daños producidos sólo dejó expedito para la mayoría de los colonos el camino de la reacción, por cruenta que esta sea (Darwin, 1833, p. 534). Respecto al pensamiento de Darwin acerca del paradigmático enfrentamiento entre salvajes y civilizados y a la inevitable desaparición de las razas oscuras, ver Brantlinger, 2003, Barta, 2005 y Lemkin, 2005.

12. Irónicamente gentlemen present en el original.

13. Esa nota extensa está identificada con la letra “y” en Tupper, 1972, pp. 40-44.

14. En la Memoria correspondiente a 1835, el Ministro de la Guerra y Marina en Chile -José Javier de Bustamante-, motivado asimismo por una crítica previa y refiriéndose a la conducta de sus tropas durante ese mismo año, elaboró un apretado resumen de los argumentos justificatorios de la barbarie estatal - colonial y republicana- que vale la pena citar completo: "Se lamentan carnicerías, que con razon hieren la sensibilidad de hombres civilizados í cristianos; se grita contra la estraccion que se hace a veces de indíjenas de ambos sexos i de todas edades. Respecto la buena fe de los que solo miran en estos actos la irritacion que produce en los bárbaros el despojo de sus hijos i mujeres; repruebo también las carnicerías que no sean necesarias en la guerra, pero, debe tenerse presente que no son aplicables a los bárbaros los principios que rijen entre las naciones civilizadas; que los jóvenes que se estraen i que se reparten entre nuestras familias, no se hacen esclavos; que solo los toman para hacerles prestar un moderado servicio, por lo regular doméstico, a trueque de educarlos en las máximas del cristianismo, i que el civilizarlos es no solo un bien inmenso para ellos sino también para el Estado, que disminuye con esta presa una raza carnicera enemiga i destructora de la parte civilizada i útil de nuestra poblacion. Las mujeres, a mas de conseguir los mencionados bienes, logran también no concebir en sus vientres fieras silvestres tanto mas peligrosas que el tigre. Nadie ignora que es lícito reducir a toda clase de enemigos, i mui particularmente a los bárbaros a un estado de absoluta nulidad, de modo que no puedan ofender. Si este pueblo se hallase rodeado de otros civilizados, si se encontrase en medio de la Europa cristiana, culta i filosófica, i con las mismas dificultades que nosotros para civilizarlos ¿deberían respetar o respetarían aquellos pueblos esos derechos de humanidad i filantropía? ¿No es evidente que lo aniquilarían para preservar sus fronteras de sus frecuentes i horrorosas incursiones? ¿I por qué entonces se acrimina tanto a nuestros soldados, porque estraen familias como presas de la guerra, porque incendian algunos campos cuando lo exije la necesidad de la campaña; porque aprehenden los ganados que el enemigo abandona en una retirada o derrota i no compadecen nuestras familias constantemente asaltadas i degolladas, nuestras fortunas robadas i nuestros campos incendiados? Tan estraño modo de discurrir solo puede esplicarse por la simpatía de nuestro corazon hacia un pueblo valiente, cuyas proezas i gloriosas hazañas han sido cantadas aun por sus enemigos; cantos que con razón inflaman nuestras almas contra los conquistadores españoles, i que en algunas personas llega a tal grado, que les hace olvidar que hoi son nuestros enemigos fieros i encarnizados, como lo fueron de los españoles i lo serán de todo el mundo." (Bustamante, 1902 [1835], p. 448). 
15. Baste repasar el Discurso de Melos (Tucídides, Guerra del Peloponeso, V, pp. 84-116) para recordar que un contendiente poderoso no tolera siquiera la neutralidad de los débiles y está dispuesto a ejercer - aun contra quienes no están en capacidad de resistirla - una violencia extrema, bajo el argumento de que, si no lo hiciera así, otros enemigos potenciales podrían sentirse tentados de enfrentarlo, estimulados por lo que se consideraría una manifestación de blandura.

16. El antiguo instituto de la guerra justa, importado desde el viejo mundo y aplicado por los invasores españoles contra distintos grupos nativos americanos (Pagden, 1988), se basaba en una falacia análoga: si quienes resistían la intromisión, intimados de rendición, no aceptaban el requerimiento de bajar las armas, podía hacérseles fuerza sin limitaciones y por todos los medios al alcance, y serían ellos mismos responsables de los daños que les ocasionase su "rebeldía", hasta el punto de ser lícito esclavizarlos y desposeerlos de sus bienes, por no haber puesto oportuno fin a la beligerancia.

17. Cuidando siempre de no traicionar el sentido que el autor quiso dar a sus palabras y sólo cuando ha sido inevitable, se modificó la colocación de los signos de puntuación con el objeto de conferirle mayor claridad a la traducción. Las comillas son las transcriptas en el libro de John Miers. Las notas al pie han sido agregadas a esta traducción para aclarar algunos nombres.

18. Quiere decir un bichador, esto es, un espía, o bombero - como también solía llamárselos en la época.

19. Así escrito por Pitrufquen. Podrá verse que, en adelante, este geónimo se repite unas veces con esta misma grafía, otras con pequeñas variantes. Siempre se trata del mismo sitio.

20. Así escrito por quila (Chusquea quila), una gramínea con cuyos tallos, que alcanzan gran altura y son resistentes, solían fabricar los indígenas el astil de sus lanzas.

21. Así escrito por Xaramillo.

22. Así escrito por Boroa.

23. Así escrito por huinca, el nombre que en mapu dungum alude en general a quienes no son mapuche y en especial a los cristianos.

24. En el texto de Miers, se aclara al pie: "El piñón es el fruto del pinus chilensis". La denominación taxonómica actual ya no es esa, sino Araucaria araucana.

25. Así escrito por contesté.

\section{ABSTRACTS}

The atrocities carried out by pro-independence forces against the Indians of southern Chile during an episode of the Guerra a Muerte, at the beginning of the 19th century, originated the production of certain testimonies linked in such a way that they allow the reconstruction of that despicable set of conducts and the reactions they prompted.

Besides accounting for the case already mentioned based on the accounts by four participantswhich accompany this introduction-, and on the justifications and comments that two of them were forced to outline after a critical intervention of an outsider, we will try to answer the question if military atrocities constituted a sub-product of a special type of conflict-the one taking place when "tribal" societies face state forces-; if there were only circumstantial excesses, condemned and punished by the superiority, or if, on the contrary, they formed a systematic behavior; and last, if the rules that governed the confrontation of European powers 
against colonial enemies in the peripheral world were or were not different from the ones ruling the wars against other Western powers.

Las atrocidades desarrolladas por fuerzas independentistas contra los indios del sur chileno durante un episodio de la Guerra a Muerte, a principios del siglo XIX, originaron la producción de ciertos testimonios eslabonados de tal forma, que permiten la reconstrucción de ese ominoso conjunto de conductas y las reacciones que ellas provocaron.

Además de dar cuenta del caso mencionado en base a los relatos de cuatro protagonistas - que acompañan este artículo introductorio- y a las justificaciones y comentarios que dos de ellos se vieron obligados a esbozar a partir de la intervención crítica de un outsider, ensayaremos una respuesta a la pregunta acerca de si las atrocidades militares constituyeron un sub-producto de un tipo especial de conflicto -el que tiene lugar cuando sociedades "tribales" se enfrentan con fuerzas estatales-; si se trataba sólo de desbordes circunstanciales condenados y penados por la superioridad o si, por el contrario, conformaban un modo de actuar sistemático; y por último, si las pautas que regían el enfrentamiento de potencias europeas con enemigos coloniales en el mundo periférico eran o no diferentes de las vigentes cuando luchaban contra otros estados occidentales.

INDEX

Palabras claves: Indígenas, Guerra civilizada, Guerra contra los bárbaros, Atrocidades Keywords: Indians, Civilized War, War against Barbarians, Atrocities

\section{AUTHORS}

\section{SEBASTIÁN LEANDRO ALIOTO}

Departamento de Humanidades de la Universidad Nacional del Sur. Bahía Blanca, Argentina. Correos electrónicos: jjimenez@uns.edu.ar; dvillar@criba.edu.ar; salioto@uns.edu.ar 